\title{
The piriform cortex and human focal epilepsy
}

\author{
David N. Vaughan ${ }^{1,2}$ * and Graeme D. Jackson ${ }^{1,2,3}$ \\ ${ }^{1}$ Florey Institute of Neuroscience and Mental Health, Heidelberg, VIC, Australia \\ ${ }^{2}$ Department of Neurology, Austin Health, Heidelberg, VIC, Australia \\ ${ }^{3}$ Department of Medicine, University of Melbourne, Melbourne, VIC, Australia
}

Edited by:

Matthias J. Koepp, University College

London, UK

Reviewed by:

Silvia Kochen, University of Buenos

Aires, Argentina

Fabienne Picard, University Hospitals

of Geneva, Switzerland

${ }^{*}$ Correspondence:

David N. Vaughan, Melbourne Brain

Centre, Florey Institute of

Neuroscience and Mental Health, 245

Burgundy Street, Heidelberg, VIC

3084, Australia

e-mail:d.vaughan@brain.org.au
It is surprising that the piriform cortex, when compared to the hippocampus, has been given relatively little significance in human epilepsy. Like the hippocampus, it has a phylogenetically preserved three-layered cortex that is vulnerable to excitotoxic injury, has broad connections to both limbic and cortical areas, and is highly epileptogenic - being critical to the kindling process. The well-known phenomenon of early olfactory auras in temporal lobe epilepsy highlights its clinical relevance in human beings. Perhaps because it is anatomically indistinct and difficult to approach surgically, as it clasps the middle cerebral artery, it has, until now, been understandably neglected. In this review, we emphasize how its unique anatomical and functional properties, as primary olfactory cortex, predispose it to involvement in focal epilepsy. From recent convergent findings in human neuroimaging, clinical epileptology, and experimental animal models, we make the case that the piriform cortex is likely to play a facilitating and amplifying role in human focal epileptogenesis, and may influence progression to epileptic intractability.

Keywords: pyriform, area tempestas, claustrum, olfaction, olfactory aura, EEG-fMRI, temporal lobe epilepsy, intracranial electrodes

\section{INTRODUCTION}

One of the important human senses and one of life's great pleasures is olfaction. From the aroma of a floral bouquet, to the flavor of a meal, and even to the familiar scent of a family member, odors provide us with rich information about our environment that influences our decisions, emotions, and memories.

The piriform cortex is a unique brain region that underlies the mechanisms that produce these olfactory experiences. It forms the major part of the primary olfactory cortex and has extensive connections with other parts of the olfactory network. It is a phylogenetically old structure that can also be found in amphibians, reptiles, and other mammals, and as such has a number of special properties. Unlike other primary cortical regions, it receives input directly from the olfactory bulb without this information being relayed through the thalamus. Additionally, it has a three-layered allocortical structure, which in human beings is otherwise only found in the hippocampus - one of the regions most implicated in focal epilepsy.

Historically, the role that the piriform cortex may play in epilepsy has not been widely recognized. In the study of human focal epilepsy, attention has mostly been given to mesial temporal structures, especially the hippocampus, and to regions of abnormal brain structure. The earliest indications that seizures may involve olfactory cortex were descriptions in the late nineteenth century of "uncinate seizures," which begin with an olfactory hallucination, and were generally thought to herald a progressive tumor of the temporal lobe. Separately, the clinical observation that some people with epilepsy have impaired olfactory function also hinted at seizure involvement of olfactory cortex. It was not until the 1980s that the particular epileptogenicity of the piriform cortex in animal models was discovered, although this finding did not have an immediate impact on human clinical epileptology.
Over the last two decades, the application of functional neuroimaging to human brain function has led to many new insights into the role of the piriform cortex in olfactory perception. In the field of epilepsy, similar techniques have emphasized a network view of seizures. Most recently, several studies using data from electroencephalography, functional MRI and nuclear medicine imaging, have suggested that the human piriform cortex may be a common node in focal epilepsy arising from different brain regions.

Therefore, it is now timely to revisit the piriform cortex and to re-examine its relevance to focal epilepsy. Beginning with a description of the anatomy and function of the piriform cortex, we go on to review the literature regarding seizures that arise within olfactory cortex in animal models and human beings, the involvement of piriform cortex in distant inter-ictal discharges, and the impact of epilepsy on olfaction. Finally, we discuss the potential for the piriform cortex to become a therapeutic target in treatment of epilepsy, and describe a case of possible piriform epilepsy where resection of the piriform cortex was performed. From consideration of these convergent lines of evidence, we argue that the piriform cortex is critically placed between limbic and cortical networks, to distribute epileptic activity, facilitate epileptogenesis, and potentially contribute toward the development of intractable human epilepsy.

\section{THE ANATOMY AND FUNCTION OF THE PIRIFORM CORTEX HAS PROPERTIES THAT PREDISPOSE IT TO EPILEPTIC SEIZURES}

Synonymously referred to as "piriform," "pyriform," and sometimes "prepyriform" (indicating the anterior piriform), the piriform cortex is the largest component of primary olfactory cortex (1-3). 
Odors are first detected in the nasal epithelium by olfactory sensory neurons. These cells project to the olfactory bulb, where inputs from similar receptor types are collected together in glomeruli. Here, they synapse onto mitral and tufted cells, which project to cortical regions via the olfactory tract (4).

Primary olfactory cortex is defined as regions that receive direct input from the lateral olfactory tract. In addition to piriform cortex this includes the anterior olfactory nucleus, olfactory tubercle, periamygdaloid cortex, and the anterior part of the entorhinal cortex (5). Beyond these regions, the olfactory network includes orbitofrontal cortex, thalamus, and insula cortex (6) and interactions with other cortical networks.

\section{ANATOMICAL LOCATION OF THE PIRIFORM CORTEX}

The human piriform cortex is located at the junction of the temporal and frontal lobes, medial to the temporal stem (7), and lines the superior and inferior banks of the endorhinal sulcus (Figures 1 and 2). The name piriform comes from its "pear-shaped" appearance in some mammals such as cats (3), although in human beings, it is a relatively smaller structure and does not have this shape (8).

In human beings, it can be subdivided anatomically into frontal or temporal lobe parts. In the temporal lobe it begins anteriorly at the level of the limen insulae, and extends posteriorly to overlie the amygdaloid nuclei (10), becoming contiguous with the cortical amygdala. Medially, the piriform cortex transitions into the perirhinal or entorhinal cortex, with this border marked more posteriorly by a small depression, the sulcus semiannularis. In the frontal lobe, the piriform cortex extends from the fundus of the endorhinal sulcus, forming a triangular region that is bounded medially by the olfactory tubercle and lateral olfactory tract (11, 12). Laterally, it merges into the insular neocortex (7).

In rats, the piriform cortex is comparatively much larger, and does not have the curvature around a deep sulcus that is seen in human beings. It lies along a rostrocaudal axis, and can be divided into an anterior and posterior part on the basis of the thickness of cell layer III, and the presence of the overlying lateral olfactory tract (3).

Histological studies in the macaque (5) indicate that the primate frontal and temporal piriform cortex correspond to the rodent anterior and posterior piriform, respectively. Despite this, some human MRI studies have divided the piriform cortex into anterior and posterior parts, using at a given $y$-axis value in the MNI coordinate system (13), or at the most anterior coronal slice where frontal and temporal lobes meet (14). Therefore, the specific criteria used in each study to subdivide the piriform should be carefully noted when comparing results.

\section{HISTOLOGY OF THE PIRIFORM CORTEX}

The defining histological feature of piriform cortex is its allocortical three-layered structure (11).

The main excitatory neuron types are superficial pyramidal cells, deep pyramidal cells, and semilunar cells. The pyramidal cells are found densely packed in layer IIb and more sparsely in layer III, with dendrites projecting up to layer I to receive inputs from the olfactory bulb $(15,16)$. Semilunar cells are a distinct population found in layer IIa, which also receive olfactory bulb inputs, and are similar to pyramidal cells but do not have basal dendrites and show a distinct firing pattern $(15,17)$.

The interneurons of the piriform cortex are mostly inhibitory GABAergic cells. They are found across all layers and multiple classes can be identified on the basis of unique electrophysiological and morphological properties $(18,19)$. They variously provide both feed-forward and feedback inhibition onto the pyramidal cells (20-23), which allows the pyramidal cells to produce temporally sparse but accurate responses to trains of olfactory bulb input.

The endopiriform nucleus is a separate population of neurons that lies deep to the piriform cortex (24), being found along its full rostrocaudal extent. These multipolar cells project widely to piriform cortex, orbitofrontal, and thalamic regions (25). In rats, the endopiriform nucleus provides a layer of integration between olfactory and gustatory processing (26). The endopiriform nucleus is also found in primates (5). In human beings, it corresponds to the parts of the ventral claustrum that lie adjacent to the piriform cortex and amygdala (27), which have been labeled "prepiriform claustrum" and "periamygdalar claustrum," respectively (7). These areas should not be confused with the dorsal (or insular) part of the claustrum (28), which has a different embryological origin and different patterns of connectivity (29).
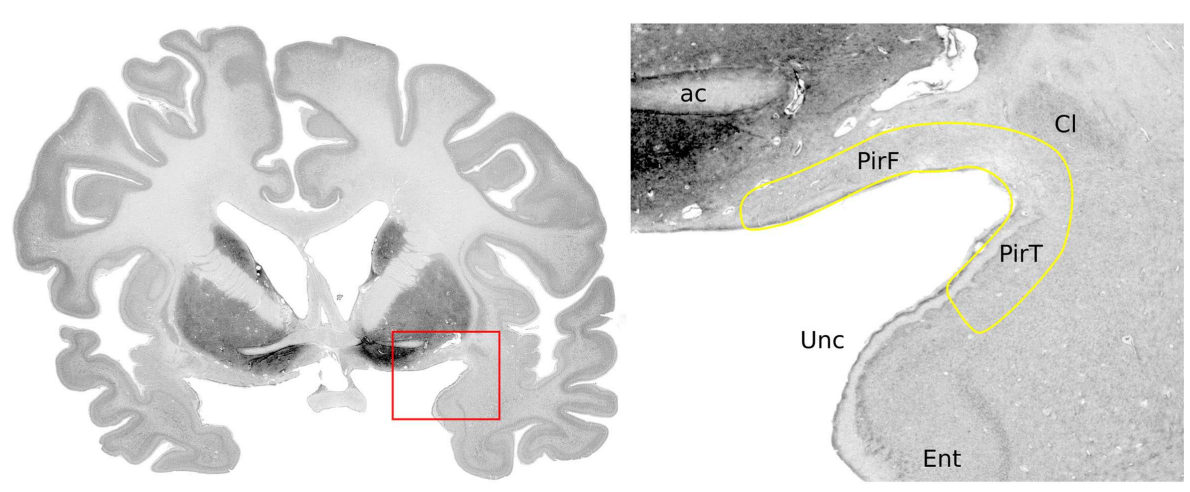

FIGURE 1 | Anatomical location of the piriform cortex. Nissl stained coronal brain slice at the level of the anterior commissure of a 65-year-old woman, from the BigBrain dataset (9). Labels were placed with reference to Mai et al. (7): ac, anterior commissure; PirF, frontal piriform cortex; PirT, temporal piriform cortex; $\mathrm{Cl}$, claustrum; Unc, uncus; Ent, entorhinal cortex. 


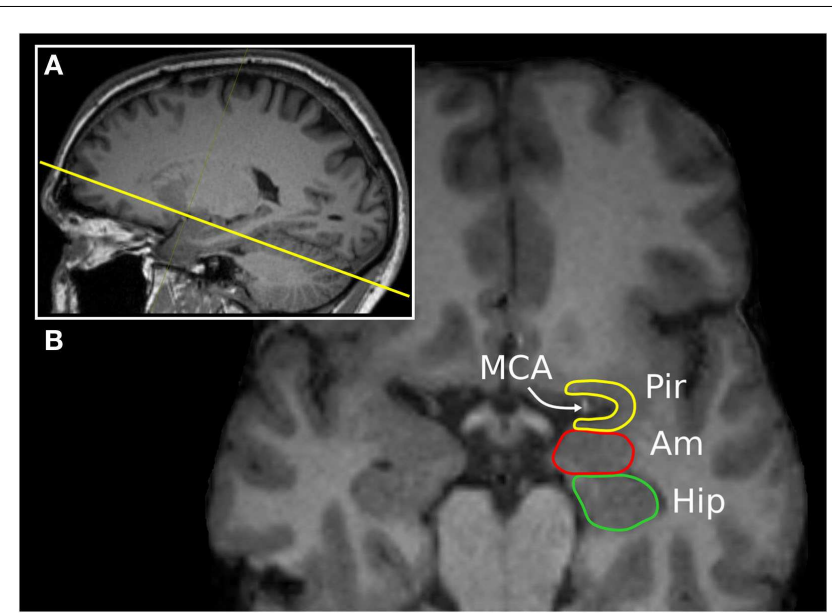

FIGURE 2 |The "piriform axis". T1-weighted MPRAGE image of a 37-year-old man, displayed in a (A) para-sagittal and (B) oblique-axial orientation, approximately $+20^{\circ}$ relative to the anterior commissure-posterior commissure axis. This orientation allows the relationship between the piriform cortex (Pir), amygdala (Am), and hippocampus (Hip) to be seen. The arrow indicates the position of the middle cerebral artery within the endorhinal sulcus.

There are several striking similarities between the structure of piriform cortex and that of the hippocampus (8). As paleocortex, both have a phylogenetically conserved structure with three layers, pyramidal neurons with similar morphology, a predominantly horizontal arrangement of fiber projections, and the presence of GABAergic interneurons. Analogous microcircuits in both piriform cortex and hippocampus provide excitation, feedforward inhibition, and feedback inhibition (30). Their main structural difference is that the piriform does not have a distinct zone that corresponds to the dentate gyrus, although the distributed semilunar cells do have morphology that is similar to granule cells.

\section{STRUCTURAL CONNECTIVITY OF THE PIRIFORM CORTEX}

The main input to the piriform cortex is from mitral cells, and to a lesser extent tufted cells, of the olfactory bulb (15). Each glomerulus in the olfactory bulb, which represents a specific olfactory chemoreceptor type, projects to a broad region of the piriform cortex to synapse with many pyramidal cells $(31,32)$. Each pyramidal cell receives input from a random selection of glomeruli, allowing cells to respond to complex features of odor mixtures (33).

Additional inputs to the piriform are from the anterior olfactory nucleus and association fibers from all other olfactory cortical regions, as well as lighter commissural projections from the contralateral piriform cortex (34). Neuromodulatory inputs include cholinergic modulation from the horizontal limb of the diagonal band, serotonergic modulation from the raphe nuclei (activating inhibitory GABAergic interneurons), noradrenergic input from the locus coeruleus (35), and dopaminergic modulation from the ventral tegmental area $(3,6)$.

Within the piriform cortex, pyramidal cells are strongly interconnected, by recurrent projections onto many other pyramidal cells (1). A single pyramidal cell has an arbor that extends over much of the piriform cortex, and in the rat, synapses with more than 1000 other cells (36). This forms a large excitatory network that requires strong local feedback inhibition to prevent runaway activation (20). However, the benefit of this arrangement of diffusely projecting inputs, combined with extensive intra-piriform connectivity, is the ability to perform pattern matching in an architecture described as "content-addressable memory" (37). This allows partially degraded patterns of input to produce consistent reproducible responses that are spatially distributed across the piriform cortex (38).

The outputs from piriform cortex pyramidal cells are widespread to cortical and subcortical regions $(15,39)$. There are strong limbic connections, especially to the entorhinal cortex and to the amygdala $(36,40,41)$, frontal lobe connections to multiple parts of the orbitofrontal cortex, and projections to agranular insular cortex (5). Important subcortical connections are to the mediodorsal nucleus of the thalamus $(42,43)$, and to the hypothalamus (44). There are also return projections from the piriform to the ipsilateral olfactory bulb, which has been likened to the cortico-thalamic circuit in other sensory modalities by some authors (45).

Based on these connections, several local recurrent circuits may provide a substrate for seizure activity (3). Firstly, the projections from piriform pyramidal cells to amygdala nuclei are returned by projections from the basolateral amygdala to the endopiriform nucleus. Secondly, projections to the subiculum link the piriform with the hippocampus, a loop that is returned to the piriform via the entorhinal cortex. Finally, piriform feedback to the olfactory bulb could also form a reentrant circuit (46).

\section{FUNCTIONAL ROLE OF THE PIRIFORM CORTEX WITHIN OLFACTORY NETWORKS}

The perception of odors involves activation of distributed cortical and subcortical networks, with regional nodes that are variably recruited depending on the nature and complexity of the olfactory task (47). Activation of the piriform cortex is seen commonly across all olfactory tasks, and it appears to be the key region for representation of the "olfactory object" (48). However, the piriform also has an important role in discrimination of odors (49), in olfactory working memory (50), and acts as an information distributing node to other brain regions (51).

Within piriform cortex, odors are represented as spatially distributed ensembles $(52,53)$. This activity is not static over time, and shows variability with the phase of the respiratory cycle (54), and especially with sniffing (55). The anterior piriform cortex encodes for molecular features of the odorant, whereas the posterior piriform encodes for the quality of the odor (14). There is rapid habituation of the piriform response to a sustained odor within seconds (56), which is a property that may be the basis for figure-ground segmentation, that is, to allow a novel odor to stand out in a complex olfactory environment (48). Piriform activation can also occur in the absence of an odorant, for example, by imagining a smell (57), or on viewing a picture or word that has a strong olfactory association $(58,59)$, which is consistent with the behavior of primary cortical regions for other sensory modalities.

Larger scale network interactions of the piriform cortex can be conceptualized as including an orbitofrontal-thalamic circuit, a limbic stream, and a fronto-temporal cortical stream. Additional 
cortical regions including the anterior insula are important for integration of olfaction into taste and flavor (60).

The orbitofrontal cortex is the principal higher-order target for piriform cortex, both directly and indirectly via the thalamus. The olfactory functions of orbitofrontal cortex include involvement in encoding for odor identity and valence, predicting anticipated olfactory stimuli (61), multisensory integration of olfactory information, assessment of reward and value signals, and a role in emotion (62). The mediodorsal nucleus of the thalamus provides an indirect pathway between piriform cortex and the orbitofrontal cortex, and is therefore well placed to provide assessment of prediction error (63), or to control olfactory attention (64). Furthermore, the connectivity between these three regions is modulated during olfactory learning (65), and by olfactory attention (66).

Limbic processing of olfactory stimuli plays an important role in memory, emotion and social behavior. Indeed the spontaneous recall of a vivid memory or emotion on smelling a particular odor is a common human experience (67). Entorhinal cortex and hippocampal activation occurs during odor identification and memory tasks, reflecting the involvement of autobiographical memory systems (68). Exposure to odors of varying degrees of pleasantness produces amygdala activation that reflects the valence (69) and also the intensity and overall emotional value of an odor (70).

The semantic network, which involves the dominant inferior frontal gyrus and its downstream influence on the fusiform gyrus and posterior temporal regions, is important for naming odors and for olfactory working memory when odors are nameable $(50,71)$. The temporal pole may be the critical area for interaction between olfactory and semantic networks based on an apparent disconnection syndrome in people with atrophy of this region (72).

\section{PIRIFORM CORTEX IS THE MOST SUSCEPTIBLE REGION TO EPILEPTOGENIC STIMULATION}

\section{PIRIFORM CORTEX SENSITIVITY TO CHEMICAL STIMULATION}

A unique property of the piriform cortex is its sensitivity for inducing epileptic seizures in experimental animals. In 1985, Piredda and Gale identified a site in the forebrain of the rat, which is exquisitely responsive to pro-convulsant chemical stimulation (73), naming it the "area tempestas" (74). Injections into this region produced bilateral clonic seizures, at much lower concentrations than are required when applied to other brain regions. Picomolar amounts of bicuculline (a GABA antagonist), carbachol (a cholinergic agonist), kainic acid (an excitatory amino acid), and micromolar concentrations of glutamate all demonstrated this effect. Preventing glutamatergic excitation via either AMPA or NMDA receptors in the area tempestas can prevent seizures, indicating that both receptor types are needed for this regions to become epileptogenic $(75,76)$.

The location of the area tempestas is deep to the anterior piriform cortex, overlapping cellular layer III and the adjacent endopiriform nucleus $(25,73)$. Some studies have shown wider sensitivity to bicuculline across both anterior and posterior piriform cortex, however, and some variability in the expression of seizures between different rat strains (77).

The area tempestas cannot be ethically demonstrated in human beings, as it is defined by an epileptic response to chemical stimulation, and is not a circumscribed anatomical structure. This study has been performed in non-human primates, however (78), using bicuculline injections into the frontal piriform cortex. A highly focal $2 \mathrm{~mm}$ region of chemosensitivity was identified. The resulting seizures consisted of automatisms and myoclonus of the mouth and face, contralateral arm clonus, salivation, behavioral arrest, and unresponsiveness, with retained postural control (79), consistent with the features of focal dycognitive and focal motor seizures in human beings.

The brain regions most affected by seizure activity triggered from area tempestas, are the posterior piriform cortex and ipsilateral entorhinal cortex (80), the olfactory bulbs, perirhinal cortex, amygdala, and the mediodorsal thalamus (81). This has been demonstrated by ictal uptake of radiolabeled glucose, and also by the ictal expression of $c$-fos and other immediate-early genes in vivo (82-84). Examination of in vitro slice preparations shows that discharge propagation from the endopiriform nucleus up to the superficial layers of piriform cortex is via longitudinally orientated rostrocaudal association fibers (85).

The posterior piriform cortex, perirhinal cortex, and mediodorsal thalamus are important regions for seizure propagation from the area tempestas. Blockade of glutamatergic transmission at these locations prevents such seizures occurring $(76,80,81)$. This is mediated primarily by the action of AMPA receptors, as selective blockade of NMDA receptors did not prevent seizures occurring.

\section{PIRIFORM SUSCEPTIBILITY TO ELECTRICAL KINDLING}

Seizures may also be produced from the piriform cortex by repeated electrical stimulation $(3,86)$. Comparison to other nearby structures shows that perirhinal cortex and dorsal claustrum also kindle as rapidly, or even faster (87). The amygdala, entorhinal cortex, and hippocampus are less sensitive (88).

The location within piriform cortex for the most rapid kindling in rodents has been reported as the central part (layer III of the rostral part of the posterior piriform cortex) (89) or in the endopiriform nucleus (90). Deep layers of the posterior piriform cortex also show the lowest afterdischarge thresholds. In human beings, these areas correspond to the frontal piriform close to the temporal stem, or to the prepiriform claustrum. Several authors have emphasized that the region corresponding to area tempestas (in the deep anterior piriform cortex) does not respond to electrical kindling as quickly $(91,92)$.

Seizures produced during the course of piriform kindling follow the same progression of motor features as kindling in other limbic regions (93). During piriform-kindled status epilepticus (type 2), where the animals show intermittent freezing and exploratory behaviors, the affected regions are the olfactory cortex and amygdala. When facial and limb clonus was also present (type 3), the hippocampus, prefrontal cortex, and insular cortex were also seen to be involved (94). Piriform kindling produces chronic network-wide changes, for example, altered potentiation at the entorhinal cortex (95), which may relate to emergence of spontaneous seizure after kindling is completed.

Therefore, the piriform cortex is highly susceptible to the induction of seizures by both chemical and electrical means, although the exact positioning of the intervention within the piriform appears to be less important, than whether an extended olfactory-limbic network can be recruited. 


\section{HUMAN SEIZURES WITH OLFACTORY AURAS TELL US ABOUT EPILEPTIC INVOLVEMENT OF THE OLFACTORY NETWORK}

Focal seizures that begin with an olfactory sensation as their earliest feature can be inferred to arise within the olfactory network. In human beings, this is a relatively uncommon type of seizure, but examining these events in detail can tells us about the patterns seizure spread from the piriform cortex. The most common olfactory ictal phenomenon is a hallucination, where the perception of an odor is unrelated to any environmental stimulus. There can also be olfactory illusions, where odors in the environment are misperceived $(96,97)$, or vaguer episodes with the quality of a reminiscence (98).

The earliest influential descriptions of seizures with an olfactory aura were by Hughlings Jackson in 1889. He described a woman who developed stereotyped episodes of a horrible smell of "dirty burning stuff" associated with a complicated visual hallucination and a feeling of suffocation. A sarcoma of the "temporo-sphenoidal lobe" was found at postmortem. Review of their diagrams shows invasion of the piriform cortex, temporal pole, amygdala, adjacent white matter, and compression of the lenticular nucleus (99). Subsequently the name "uncinate group of fits" was given to seizures beginning with a crude sensation of smell or taste, and variably associated with oral automatisms and the "dreamy state" $(100,101)$. Importantly, this label was intended to convey that these seizures involved a broad region of which the uncus is a part, and should not be interpreted as a precise anatomical localization.

\section{CLINICAL CHARACTERISTICS OF SEIZURES WITH AN OLFACTORY AURA}

Estimates of the prevalence of olfactory epileptic auras are quite variable due to patient selection criteria and how auras were ascertained. Considering all people with focal epilepsy, rates between 0.9 and $8.1 \%$ are reported (102-107). If restricted to epilepsy arising from the temporal lobe, with or without selection for epilepsy surgery, olfactory auras are present in $0.6-16 \%$ (108-113). Out of people who experience an epileptic aura of any kind, between 19 and 30\% have an olfactory aura (114-116).

The character of olfactory hallucinations is usually unpleasant, and may be described as rotten, fetid, sulfurous, or burned (110, 117). This may correspond to epileptic activity causing particularly intense activation of the piriform cortex and amygdala, as occurs with non-pathological smelling of unpleasant odors in the environment (57). Less commonly the olfactory hallucination is neutral and only rarely pleasant $(102,106)$. Some descriptions have emphasized the "crude" nature of the experience, without having the full experiential quality of smelling an actual odor (100). Indeed many patients find the hallucination "indescribable," or refer to it as "like" the aroma of something else (98), suggesting that the engagement of the olfactory network is not the full physiological pattern of olfactory perception. The olfactory hallucination is usually pervasive, but in rare cases is experienced as coming from one nostril (98), or from one side of the body (118), which may be due to lateralized involvement of primary olfactory cortex or activation of the superior temporal gyrus (12).

A particular "rhinostomal" sensation of tickling or pressure in the nose or pharynx often accompanies olfactory hallucinations
(98). This may be analogous to the trigeminal nerve stimulation that is physiologically produced by many odorants. A similar sensation of unilateral itching inside the nose has also been triggered by electrical stimulation near the olfactory bulb (119).

Olfactory auras may be accompanied by other aura symptoms, pointing to epileptic activation of multiple sensory or cognitive networks. The association of olfactory auras with ictal emotion (120) suggests epileptic co-involvement of olfactory and limbic networks. Olfactory auras are often accompanied by gustatory or psychic auras when the underlying epileptogenic lesion is a tumor $(102,105,106)$. However, patients with mesial temporal sclerosis tended to have epigastic sensations and autonomic phenomena accompanying the olfactory aura (110), indicating different spread patterns depending on etiology.

When there are multiple aura types during the same seizure, the order of progression indicates the direction of epileptic spread. In a small case series, one patient with a neocortical temporal lesion had an olfactory aura followed by a sensory aura. Another similar patient had a concurrent olfactory and psychic aura (116). These examples may represent epileptic spread from the olfactory network into cortical networks and limbic networks respectively. Two further patients with mesial temporal sclerosis were described in this cohort. The first had a concurrent olfactory-abdominal aura, and the second had a progression of autonomic, sensory, and psychic symptoms before the olfactory aura emerged. This latter case is an example where the seizure likely began outside the olfactory network, but it became engaged as the seizure progressed. In patients with mesial temporal sclerosis, imaging data has shown that patients with an olfactory aura are more likely to have an accompanying abnormality of the amygdala (121). This suggests that the amygdala may be a possible gateway for seizure spread from mesial temporal into olfactory networks.

The etiology of seizures with an olfactory aura is commonly found to be a tumor $(102,108,113)$ or mesial temporal sclerosis $(109,110,114)$, with debate over which of these is more common. Other cases have been caused by intracerebral hemorrhage (122), middle cerebral artery aneurysm (118), arteriovenous malformation, head injury $(103,123)$, and previous encephalitis (124). In rare cases, there is no obvious cause and no structural abnormality is found on MRI (110). It is the anatomical location of these lesions, rather than the nature of the pathology, that is most relevant to the occurrence of olfactory auras, although the close relationship of the middle cerebral artery to the piriform cortex at the endorhinal sulcus should be noted.

\section{THE POST-ICTAL NOSE-WIPE COULD BE EXPLAINED BY AN ICTAL RHINOSTOMAL SENSATION}

A movement of the hand to wipe or rub the nose is often observed in the immediate post-ictal phase following focal seizures. It is most common in seizures from the mesial temporal lobe, occurring in more than half of mesial temporal lobe epilepsy patients having video-EEG prior to surgery $(125,126)$, but it may also be seen in frontal lobe epilepsy. It may be accompanied by postictal coughing (127), and does not occur if the seizure evolves to a bilateral convulsion (119). Typically, the hand ipsilateral to the seizure focus is used, because of contralateral neglect or weakness (125). 
We hypothesize that the ictal nose-wipe is a voluntary action performed in response to the ictal rhinostomal sensation, as a result of epileptic activation of olfactory regions. Geyer et al. (119) have previously suggested that olfactory hallucinations and postictal nose-rubbing are linked by epileptic involvement arising from the uncus. However, many patients with post-ictal nose-wiping do not have awareness of any olfactory aura (128). Hirsch et al. (125) proposed that the nose-wipe is caused by increased nasal secretions from ictal activation of autonomic pathways, particularly the amygdala (129). Intracranial EEG recordings from the amygdala can show early ictal involvement in seizures, which include nosewiping, but this is neither sufficient nor necessary for nose-wiping to occur (130).

\section{LESION “LOCALIZATION” IN SEIZURES WITH AN OLFACTORY HALLUCINATION}

The anatomical location of epileptogenic lesions indicates how seizure discharges gain access to the olfactory network. It should not be assumed however that the lesion equates to the location where the aura is produced, as emergence of an olfactory percept likely requires coordinated activation of multiple olfactory brain regions $(131,132)$.

Olfactory auras are not lateralizing, and are associated with similar rates of left and right-sided lesions (107, 110, 111). The most common location is in the anteromesial temporal lobe, with some tumors extending into the frontal lobe $(102,108)$. Other series have found only temporal lobe lesions, both with and without involvement of mesial temporal structures $(107,114)$. In a few cases, lesions have been isolated to the amygdala $(102,110,123)$.

The case most strongly indicating primary involvement of the piriform cortex is provided by Mizobuchi et al. (118). The cause of seizures was a $1 \mathrm{~cm}$ aneurysm of the middle cerebral artery, "between the tip of the right temporal lobe and the orbitofrontal gyrus." MRI clearly shows compression of both frontal and temporal piriform cortex, although the authors do not label it as such. The olfactory aura was followed by a phase of retained awareness and speech, but impaired memory, suggesting limited seizure spread to either autobiographical (limbic) or perhaps semantic (cortical) memory networks.

Whether purely frontal lobe lesions can cause seizures with an olfactory hallucination is less clear, even though this is often said to be the case $(106,133)$. In some series of patients with frontal lobe epilepsy, confirmed by curative frontal lobe resection, there have been no instances of olfactory auras (134). Possible cases include one out of a series of 28 patients with extra-temporal focal epilepsy studied by intracranial stereo-EEG, although this patient was cured by temporal lobe resection (135). Another study described two patients under the heading of an olfactory-gustatory-fear aura, who had frontal lobe lesions at the supplementary motor area and lateral premotor cortex, respectively (105).

The only unequivocal report of a frontal lobe lesion causing an epileptic olfactory aura was due to an abscess at the frontal pole (136). Several pathways to involvement of the olfactory network are possible here; seizure activity could have spread from the lesion into adjacent orbitofrontal cortex, activity could have propagated via the uncinate fasciculus into the temporal lobe, or there may have been local inflammatory or epileptic irritation of the olfactory tract. Of these sites, an olfactory hallucination has been produced most consistently by electrical stimulation of the olfactory tract (137).

\section{ICTAL EEG IN SEIZURES WITH OLFACTORY AURAS}

Scalp EEG during seizures with an olfactory aura has shown epileptiform discharges at the ipsilateral sphenoidal electrode, consistent with seizure involvement of mesial temporal structures $(102,120$, 138). This confirms that these olfactory hallucinations are epileptic in origin, and are not due to mere inter-ictal dysfunction of the olfactory network.

Intracranial EEG recording has much greater sensitivity for detecting focal epileptic activity, but sparse spatial sampling often limits the precision of localization. Electrodes have typically been placed into mesial temporal structures, over the lateral and inferior temporal lobes, and into frontal regions, with the piriform cortex seldom being an explicit target for recording.

The following five reports demonstrate intracranial recordings of epileptic activity in the temporal and/or frontal lobe associated with an olfactory aura, although it must be noted that no cases had an electrode directly in piriform cortex. (i) Epileptic activity at the amygdala and hippocampus was seen in a patient who had a temporo-basal cyst and habitually experienced an epigastric-olfactory-gustatory aura (139). (ii) Discharges from the hippocampus were seen in two patients who had mesial temporal sclerosis, during an olfactory aura (140). (iii) A patient with a more elaborate aura, consisting of initial déjà vu then an olfactory hallucination, detachment, fear, and auditory illusions, had ictal rhythms that were widespread across the right hippocampus, amygdala, anterior cingulate, middle, and superior temporal gyri (141). (iv) A patient who experienced seizures with a sense of foreboding, dissociation, and a "sickening" smell, showed initial activity in superior temporal electrodes, with consistent spread of the discharge into orbital areas (135). (v) A further three patients had simultaneous epileptic activity in the temporal and orbitofrontal regions during the olfactory aura, however, no aura occurred in seizures when only the frontal lobe was involved, or when temporal lobe involvement was late (142).

Therefore, the seizures that produce olfactory hallucinations typically involve relatively widespread activity in the orbitofrontal and anterior temporal lobe. Although recordings directly from piriform cortex were not obtained in these cases, we infer its involvement from its location at the center of the regions that were sampled, and its core role in olfactory perception.

\section{INTRACRANIAL STIMULATION DEMONSTRATES SITES THAT MAY PRODUCE AN OLFACTORY HALLUCINATION}

Direct electrical stimulation of the human brain, either during surgery or via long-term implanted electrodes, has identified locations that may trigger an olfactory sensation similar to the epileptic aura. Findings are somewhat variable, and several large studies of temporal lobe stimulations have induced no olfactory sensations at all (143).

The earliest reports are of a crude sense of smell produced by stimulation of the uncus, or of the olfactory bulb (144). Only a few authors have applied stimulation near the piriform (145). Overall, stimulation of the amygdala is the location that most often produces an olfactory percept, although reproducibility in individual patients is not consistent (145-148). 
In one patient with epilepsy, amygdala stimulation produced an afterdischarge that propagated to the hippocampus, at the same time accompanied by a "foul rotten odor" typical of their usual seizures. Transection adjacent to the amygdala prevented propagation to the hippocampus, but the olfactory aura on amygdala stimulation still occurred. The patient became seizure free after resection of the amygdala and overlying anterior cortex, including temporal piriform cortex (123). This suggests that either amygdala activity itself or spread into the adjacent piriform cortex is the relevant pathway, and that amygdala-to-hippocampus spread is less important.

Stimulation over the orbitofrontal cortex does not elicit an olfactory hallucination, unless the electrodes are in a position to stimulate the olfactory bulb or tract (137). The induced odor is always unpleasant. This could be because a large number of fibers are stimulated through the use of macro-electrodes, and the subsequent activation of olfactory cortex, which is relatively intense.

\section{SEIZURES MAY INVOLVE THE PIRIFORM CORTEX WITHOUT AN OLFACTORY HALLUCINATION}

An intriguing possibility is that some human seizures may arise from the piriform cortex, without being accompanied by an olfactory aura. This has been demonstrated in a single case of reading epilepsy, that was intensively investigated using combined imaging techniques and advanced statistical modeling (149). Clinically, covert reading induced peri-oral myoclonus, however, no accompanying olfactory hallucination was described. Both magnetoencephalography and EEG-fMRI demonstrated seizure-related activity at the dominant left premotor cortex, with fMRI showing a more extensive network of activation involving left piriform cortex, left thalamus, and right inferior frontal gyrus, consistent with findings from a larger group of people with reading epilepsy (150). Modeling of $\mathrm{fMRI}$ timecourses showed the earliest BOLD response was in the left piriform cortex. An effective connectivity analysis identified a model where piriform cortex activity drives activation of the premotor cortex and then onto other regions. While this case report suggests a possible role of piriform cortex in driving seizures into premotor regions, whether this is generally the case in patients with reading epilepsy remains to be confirmed.

\section{PIRIFORM CORTEX IS A NODE FOR SECONDARY SPREAD OF INTER-ICTAL DISCHARGES IN HUMAN BEINGS}

Beyond its role in olfactory auras, the piriform cortex may be one of the common pathways for propagation of epileptic discharges in focal epilepsy. The first study to suggest this used combined encephalography and functional MRI (EEG-fMRI) (151). They studied a diverse group of 19 patients, who had focal epilepsy arising from all lobes. After aligning the epileptic side between patients, a second-level random effects analysis was performed, and showed significant clusters with peak BOLD response overlying the ipsilateral piriform cortex (Figure 3A). Regions of

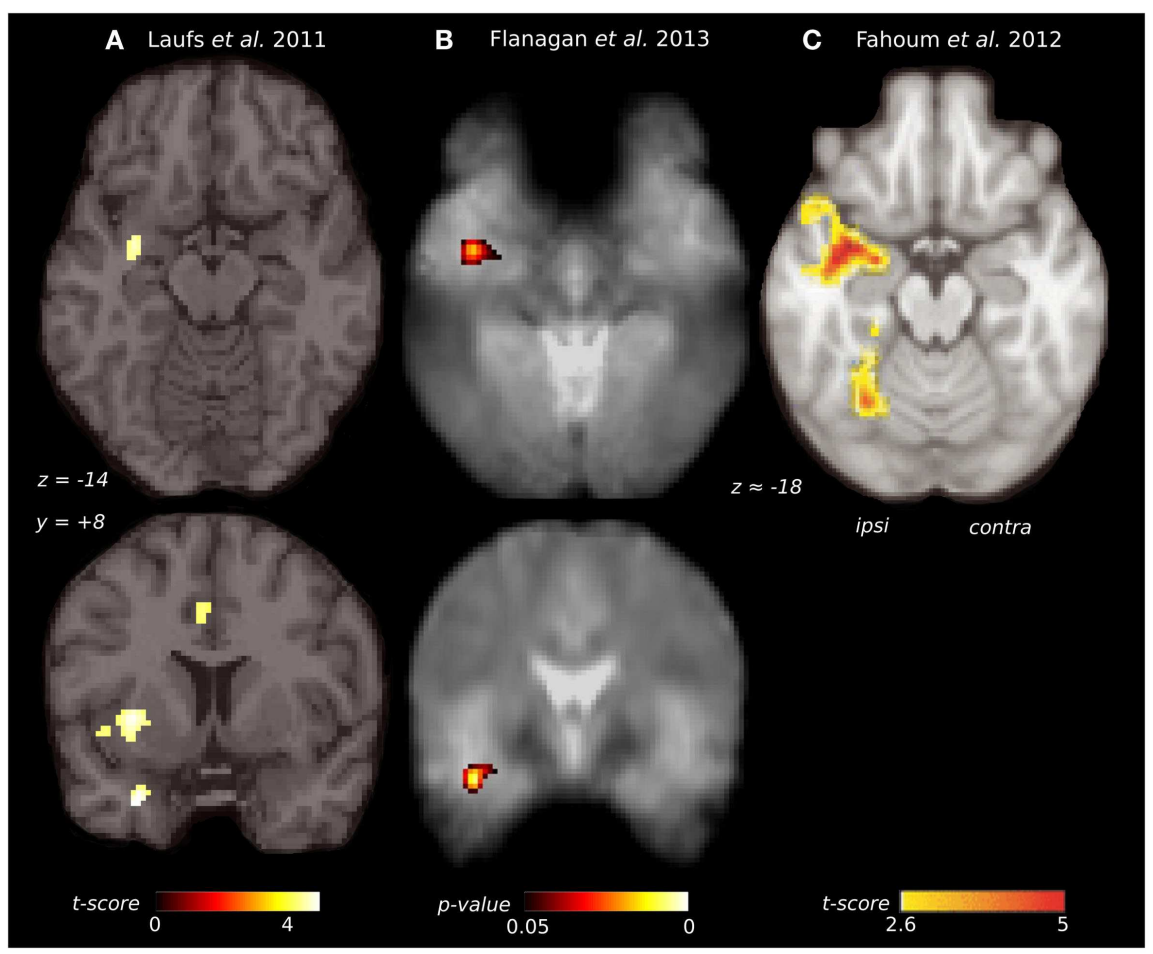

FIGURE 3 | Comparison of piriform cortex activation in EEG-fMRI studies of focal epilepsy. (A) Group EEG-fMRI analysis for a mixed cohort of focal epilepsy at threshold $p<0.001$ ( $n=19$ ). (B) Group EEG-fMRI random effects analysis for a mixed epilepsy cohort $(n=27)$ showing $p$-values $<0.05$ FWE corrected. Reproduced from Flanagan et al. (153) with permission from Elsevier. (C) Group EEG-fMRI analysis of a purely TLE cohort ( $n=32$ ), with hemodynamic response function peaking at $5 \mathrm{~s}$ ( $p<0.05$ cluster corrected). Reproduced from Fahoum et al. (154) with permission from Wiley Periodicals, Inc. (C2012 International League against Epilepsy. 
activation also extended over the ipsilateral dorsal claustrum and anterior cingulate. The interpretation is that these areas are activated by inter-ictal discharges in many individuals, regardless of the site where the discharge begins. A recent paper has commented that the peak coordinates in this study favor activation of the dorsal claustrum (152), although the shape of the activation clusters do not entirely follow this structure, and activation specifically within the thin sheet of the claustrum would be difficult to resolve at this fMRI resolution.

Replication of this analysis using functional MRI acquired at $3 \mathrm{~T}$, in an independent cohort of 27 patients with heterogeneous epileptic foci, again identified a common area of temporal lobe activation, in the region of the ipsilateral piriform cortex (Figure 3B) (153).

A further EEG-fMRI study analyzed subjects with focal epilepsy, this time grouped by lobe $(154,155)$. In total, 32 patients had temporal lobe epilepsy, 14 frontal lobe epilepsy, and 20 posterior quadrant epilepsy. The activations detected by this approach were more extensive than in previous studies, suggesting greater homogeneity of epileptic networks within these selected groups. The temporal lobe epilepsy cohort showed an ipsilateral network of activation over the insula, claustrum, temporal piriform cortex, and amygdala (Figure 3C), as well as anterior hippocampus, mid-cingulate and cerebellum. The frontal lobe epilepsy group did not have significant activation of piriform cortex, although other sites of activation were seen in the mid-cingulate, ipsilateral frontal operculum, thalamus, and cerebellum. The posterior quadrant epilepsy group had no significant regions of common activation (154).

Taken together, these results indicate that inter-ictal discharges arising from the temporal lobe, and perhaps those from the frontal lobe, can produce common activation within the piriform cortex, along with other ipsilateral brain regions. This occurs in the absence of positive olfactory symptoms. Whether discharges from parietal and occipital lobe foci also engage the piriform cortex in this way requires further clarification.

\section{PIRIFORM CORTEX IS SUSCEPTIBLE TO SEIZURE-INDUCED INJURY AND FACILITATES PROGRESSION OF FOCAL EPILEPTOGENESIS}

\section{STATUS EPILEPTICUS INJURES THE HUMAN PIRIFORM CORTEX}

A characteristic property of the piriform cortex is its tendency to sustain neuronal injury as a consequence of repeated seizures. This is demonstrated by three unusual human cases of status epilepticus, in people who had no prior history of epilepsy (156). The causes were neuroleptic malignant syndrome, carcinomatous meningitis, and unknown, respectively. The duration of status epilepticus on EEG was between $9 \mathrm{~h}$ and 3 days. The three individuals died between 11 and 27 days after status epilepticus. At postmortem, neuronal loss was most prominent in the piriform cortex, hippocampal subfields, and amygdala, although with some asymmetry and variability between individuals. Milder widespread changes were seen in the deep layers of the neocortex, the Purkinje cell layer of the cerebellum, and the dorsomedial nucleus of the thalamus. Glutamate-mediated excitotoxicity has been suggested as the mechanism of neuronal necrosis, by analogy to animal studies of status epilepticus.
Domoic acid, a glutamate analog, has also been seen to cause neuronal toxicity in the human piriform cortex following status epilepticus. The most prominent injury is to the hippocampus, which is likely related to kainate receptor excitotoxicity (157), but more widespread injury also occurs, affecting the piriform cortex, olfactory tubercle, amygdala, mediodorsal thalamus, and nucleus accumbens (158). The same pattern is seen with domoic acid in experimental animals (159), although one study in rats has suggested that the most significant early changes are in the olfactory bulb and endopiriform nucleus (160). The mechanism of piriform cortex injury in these cases may be either the direct effect of the toxin, or the kindling effect of repeated seizures.

\section{INDUCED STATUS EPILEPTICUS INJURES THE PIRIFORM CORTEX IN EXPERIMENTAL ANIMALS}

Status epilepticus induced by pilocarpine or kainic acid also produces early injury to the piriform cortex, even though greater attention is often given to the hippocampus in these studies.

Rodents treated with pilocarpine, a potent muscarinic agonist, are often presented as a model of human chronic temporal lobe epilepsy $(161,162)$. Following systemic administration of pilocarpine, there is an initial phase of limbic status epilepticus, then a latent period of several weeks, before spontaneous recurrent seizures develop. Here, we discuss the initial phase only. Although many brain regions are affected, serial MRI shows the earliest changes in the piriform and entorhinal cortex, as early as $6 \mathrm{~h}$ after the status epilepticus $(163,164)$, reflecting cellular edema, and neuronal loss in these regions (165). Cellular hyperactivity, imaged by $c$-fos expression, is first seen (at $30 \mathrm{~min}$ ) at the piriform cortex, olfactory tubercle, thalamus, caudate, and lateral habenula, with later changes (at 60-90 min) in hippocampus, amygdala, and basal ganglia (166). Early neuronal loss and gliosis occur in the piriform cortex, hippocampus, amydala, thalamus, and substantia nigra (167). More specifically within the piriform cortex and endopiriform nucleus, it is the posterior two-thirds that are affected, which reflects the pattern of arborization of efferents from the endopiriform nucleus (168). It is primarily the pyramidal cells that are lost, but immunocytochemistry also shows loss of distinct populations of piriform GABAergic interneurons, some of which have analogous labeling to hippocampal basket cells (169). Involvement of the piriform cortex may be explained by cholinergic innervation from the diagnonal band of Broca (170), or the tendency of piriform cortex to produce burst firing with muscarinic antagonism (171). Subsequent neuronal loss may be caused by excitotoxic glutamate release and neuronal calcium influx during seizures (172) or by concurrent ischemic mechanisms (173).

Kainic acid is an analog of glutamate, which like pilocarpine, produces limbic status epilepticus after systemic administration. This results in damage to the hippocampus, amygdala, piriform cortex, entorhinal cortex, thalamus, and septal regions, although with some differences in timing relative to the pilocarpine model (174). The regions showing greatest oxidative stress are the piriform cortex, hippocampus, and cerebellum (175), and the greatest subsequent volume loss is again in the posterior olfactory cortex and amygdala, with loss of approximately one-third loss of neurons in these areas (176). GABAergic neurons of the piriform cortex also show a unique property in this situation, of increasing 
mRNA expression for glutamate decarboxylase (GAD), perhaps in an attempt to control excitotoxic injury in the face of ongoing neuronal loss (177). The mechanisms of piriform cortex injury here are either the direct excitotoxic effect of the kainic acid, or via release of glutamate during the seizure, and although disentangling these possibilities is difficult, the ability of specific blockade of glutamatergic NMDA receptors to prevent neuronal loss in this model favors the latter (178).

Lesion studies of the piriform cortex further indicate that piriform cortex involvement may be a critical for the development of chemically induced seizures. In the administration of soman, a powerful inhibitor of acetylcholinesterase that causes seizures via stimulation of muscarinic and nicotinic receptors, pre-lesioning of posterior piriform cortex or perirhinal cortex significantly increased the latency to seizure onset. This prevention did not occur with ablation of the amygdala, entorhinal cortex, or hippocampus (179).

\section{AMYGDALA KINDLING CAUSES CHANGES WITHIN PIRIFORM CORTEX}

Neuronal injury at the piriform cortex, and subsequent change in its function, is seen following electrical kindling at sites such as the amygdala or hippocampus (3). During amygdala kindling, afterdischarges are induced from the piriform from the very first stimulation, indicating the high connectivity from the amygdala and propensity of piriform cortex to sustain epileptic discharges (180). During this process, neuronal loss not only occurs at the primary kindling site, but is also at the central piriform cortex, particularly with loss of GABAergic interneurons $(181,182)$. Once amygdala kindling is completed, there is increased background firing of neurons in the upper layers of the central piriform. These are most likely inhibitory interneurons, which have pathologically reduced sensitivity to glutamate, and are compensating for loss of feed-forward inhibition $(183,184)$. There is also increased excitability at the piriform cortex, which is demonstrated by a significant drop in its afterdischarge threshold (185).

Many other changes occur in the piriform cortex following amygdala kindling, which may underlie this increased excitability. These include expression of markers of synaptogenesis on excitatory neurons $(186,187)$, altered regulation of glutamate transporters (188), abnormal transcription of AMPA and GABA receptor subunits $(189,190)$, altered expression of voltage gated potassium channels on multipolar inhibitory interneurons (191), alteration of chloride transport that further exacerbates the failure of GABAergic inhibition (192) and proliferation of astrocytes (193). The most recent observation has been the breakdown of perineuronal nets around specific interneurons, leading to increased sites of GABA release, and the pathological rewiring of local microcircuits (194).

\section{PIRIFORM CORTEX FACILITATES EPILEPTOGENESIS IN THE AMYGDALA KINDLING MODEL}

As the epileptic state develops, the piriform cortex plays a key role in the facilitation and distribution of kindled afterdischarges. Early in the process, uptake of radiolabeled deoxyglucose during seizures shows involvement only of the amygdala and the regions it is directly connected to, including the piriform. After kindling is completed, much more widespread activation is seen during seizures, affecting substantia nigra, thalamic nuclei, basal ganglia, and bilateral neocortex $(3,195)$. Similarly using $c$-fos expression as a marker of cellular activity, a limited expression of seizures is seen in the early phases, confined to either a unilateral amygdala-insulatemporal network, or a bilateral amygdala-hippocampal network. Following kindling, this becomes much more extensive involving extensive amygdala, olfactory, hippocampal, and neocortical regions bilaterally (196). Furthermore, during amygdala kindling, spontaneous discharges arise most frequently from the piriform cortex (197). Together this suggests that the piriform is involved in converting the kindled seizure discharge from one that is confined to the stimulation site and immediate projections, into an event having more widespread distribution (3).

The role of the piriform cortex in facilitating epileptogenesis can be further explored by blocking it prior to the kindling process. This approach has given variable results depending on the site and method of piriform inhibition. Permanent lesions that alter the progression of amygdala or hippocampal kindling have included the destruction of the central piriform cortex with ibotenate (198, 199), electrical ablation of the ipsilateral piriform, and knife-cut disconnection of the anterior piriform (200). These increased the number of stimulations to achieve kindling, prolonging either during the early or later phases, and increased the post-kindling seizure threshold. Other approaches such as injecting the anterior piriform, or bilateral radio-ablation of the area tempestas did not alter kindling (91), re-enforcing that it is the posterior piriform, which is the critical site for discharge propagation.

Chemical modulation of the piriform cortex also can alter the course of amygdala kindling. Microinjection of a $\mathrm{GABA}_{\mathrm{A}}$ receptor agonist, or an NMDA receptor antagonist reduces the duration of kindled afterdischarges $(92,201)$. Microinjection of vigabatrin, an antiepileptic medication, which elevates local GABA levels, inhibited seizures in previously kindled animals, showing greatest effect when applied to the central piriform cortex $(201,202)$. Finally, local application of adenosine to the piriform cortex (an endogenous neurotransmitter that may have an antiepileptic effect by decreasing glutamate release), inhibited kindling from both the amygdala and the hippocampus $(203,204)$. Kindling of the amygdala can also be blocked by lesions at the dorsal claustrum (205), demonstrating that the piriform cortex is not the only critical structure in limbic epileptogenesis.

In summary, the available evidence shows that either chemical or repeated electrical stimulation applied to limbic sites can produce complex changes in the piriform cortex, which ultimately results in increased piriform cortex excitability. Therefore, the piriform cortex can provide a pathway for focal epileptogenesis, via the facilitation and widespread distribution of epileptic discharges.

As a corollary, we should consider whether the piriform cortex has any influence on the progression to intractable epilepsy. Defined in clinical populations as ongoing seizures despite adequate trials of two appropriate and tolerated medications (206), medication resistance in epilepsy is likely to be a multifactorial process (207), and is often related to the intrinsic severity of the epilepsy syndrome (208). The epilepsy most strongly associated with piriform cortex involvement is temporal lobe epilepsy (as discussed in Sections "Human Seizures with Olfactory Auras Tell us About Epileptic Involvement of the Olfactory Network" and 
"The Impact of Epilepsy on Olfaction and its Imaging Correlates in Human Beings"), which has high rates of medical intractability that may either be present from the onset, or develop over time (209). Hippocampal atrophy is a particular marker for progression to intractability in this group, and an association between hippocampal atrophy and piriform atrophy has been noted (10). High initial seizure frequency and the occurrence of status epilepticus are known to cause piriform cortex injury and are also risk factors for intractability (210). A further mechanism of pharmacoresistance is the expression of the multi-drug transporter P-glycoprotein, which can cause efflux of medications from epileptogenic sites (211). Marked P-glycoprotein expression has been seen at both hippocampus and piriform cortex in phenobarbitoneresistant rat models (212). However, there may be significant interspecies variation for this mechanism, and recent in vivo human imaging of P-glycoprotein did not detect significant changes at the piriform cortex (213). Lastly, alterations in neural networks due to axonal sprouting and synaptic reorganization may contribute to pharmacoresistance (214). Therefore, the piriform cortex has anatomical and functional characteristics that position it to contribute to the phenomena associated with intractability.

\section{THE IMPACT OF EPILEPSY ON OLFACTION AND ITS IMAGING CORRELATES IN HUMAN BEINGS}

\section{OLFACTORY FUNCTION IS IMPAIRED BY FOCAL EPILEPSY}

A common theme in focal epilepsy is that overlap of epileptic regions with sensory networks produces dysfunction of that modality (215). In patients with temporal lobe epilepsy, many aspects of olfactory function are abnormal (115), which is most likely caused by epileptic involvement of the olfactory network.

The threshold for detection of odors is normal for people with temporal lobe epilepsy, on standard testing with n-butanol or phenyl ethyl alcohol (124, 216-220). However, some studies have found reduced sensitivity for odors by using broader panels of odorants $(115,221)$. The occurrence of seizures may transiently alter odor detection thresholds, with heightened olfactory sensitivity during the seizure prodrome, and reduced sensitivity lasting for hours or days in the post-ictal phase (115).

In contrast, odor discrimination, memory, and identification/naming are all commonly impaired in temporal lobe epilepsy. Odor discrimination relies on the piriform cortex, orbitofrontal regions, and the hippocampus (222), and failure on this task reflects dysfunction of these networks (219, 220, 223, 224), although this deficit has not been confirmed on all studies (217). Single-nostril presentation of odorants lateralizes the deficit to the same side as the epileptic focus (220).

Memory recall of odors activates an extensive network including olfactory cortex, semantic networks, and attention systems (13). Impaired odor memory has been demonstrated with a variety of protocols $(216,220)$. Some studies have detected abnormality only in left sided (225), or in right-sided temporal lobe epilepsy (226), probably related to the relative involvement of the autobiographical memory network versus semantic networks on a given task (227). Single-nostril presentation again shows an ipsilateral deficit, being more pronounced in left sided epilepsy (223).

Identification of odors, for example by selecting from a list of names, is also impaired $(124,217,219)$. This deficit occurs equally with left and right-sided temporal lobe epilepsy $(216,225)$ or can have a right temporal lobe predominance (218). Correct odor identification activates olfactory, limbic and semantic networks, plus other primary cortical areas (68), but may have more pronounced involvement of the non-dominant hemisphere when non-verbal identification is used $(228,229)$.

Olfactory function in patients with generalized or extratemporal focal epilepsy has rarely been tested. Impaired odor identification was found in a mixed group mostly with generalized epilepsy (225). Another group with extra-temporal epilepsies had normal odor detection, discrimination, and memory (220). This may be surprising in light of the EEG-fMRI findings indicating common involvement of the piriform cortex in some extratemporal focal epilepsies, although more behavioral data is clearly needed to address this discordance.

\section{NEUROIMAGING OF PIRIFORM CORTEX SHOWS OLFACTORY DYSFUNCTION IN FOCAL EPILEPSY}

Multiple neuroimaging modalities have shown changes to piriform cortex in focal epilepsy, which parallel the dysfunction of olfactory processing we have described above.

Volumetric MRI shows piriform cortex atrophy in temporal lobe epilepsy. This was examined by manual tracing of the temporal and periamygdaloid cortex, identifying reduced volume on the same side as the epileptic focus (10). This effect is greater with right-sided epilepsy. Piriform cortex atrophy is bilateral in a subgroup of patients with left temporal lobe epilepsy. There is a significant correlation between atrophy of piriform cortex and atrophy of the hippocampus, amygdala, and entorhinal cortex, indicating that the piriform changes are not isolated, but are part of a distributed network effect. The olfactory bulb volume is also reduced in temporal lobe epilepsy (230), which may be a "top-down" effect driven by pathology within primary olfactory cortex.

In frontal lobe epilepsy, voxel-based morphometry has surprisingly shown increased volumes of the piriform cortex and amygdala bilaterally compared to controls, and no regions of atrophy were found (231). The meaning of increased gray matter volume in this context is uncertain.

Chemosensory evoked potentials (CSERPs) can tell us about the relative timing of olfactory processing. In temporal lobe epilepsy, evoked potentials are delayed when an odor is presented to the side of the epileptic focus (232). This effect was most pronounced in right temporal lobe epilepsy, reflecting the relative importance of the right hemisphere in olfaction.

The functional activity of olfactory brain regions in epilepsy has been investigated with positron emission tomography (PET) using an $\left[{ }^{15} \mathrm{O}\right]-\mathrm{H}_{2} \mathrm{O}$ tracer (233). People with temporal lobe epilepsy failed to activate the ipsilateral piriform cortex, amygdala, and anterior insula when smelling various odors. Furthermore, when smelling familiar (nameable) odors patients with left mesial temporal lobe epilepsy failed to activate left inferior frontal cortex, which the authors suggest may be due to impairment of connections between olfactory and semantic networks.

PET using a $\left[{ }^{11} \mathrm{C}\right]$-flumazenil tracer has been used to probe $\mathrm{GABA}_{\mathrm{A}}$ receptor expression. In a group of patients with focal epilepsy from all lobes, flumazenil binding was inversely correlated 
with seizure frequency in the frontal piriform cortex (151). The finding that people with more seizures have the weaker expression of $\mathrm{GABA}_{\mathrm{A}}$ receptors, suggests that altered GABAergic inhibition in the piriform cortex may be a consequence of increased seizure frequency, and potentially even a cause for frequent seizures.

\section{CAN STIMULATION OF THE PIRIFORM CORTEX BE USED THERAPEUTICALLY?}

\section{ABORTING SEIZURES WITH AN OLFACTORY STIMULUS}

As early as 1881, Gowers suggested that the application of a strong aroma, such as ammonia or amyl nitrite, may in some cases arrest the course of a seizure (234). Other historical accounts have described the use of other unpleasant odors such as "shoesmell" (235). Setting aside any direct pharmacological effect of these odors, a plausible hypothesis is that strong physiological activation of olfactory cortex can temporarily prevent or disrupt the progression of epileptic discharges. An alternative interpretation would be that the smell produces a change in cognitive state, for example alertness, which is less permissive for seizures to evolve.

In a detailed clinical account of this technique, Efron describes a woman with "uncinate" seizures, who had an exceptionally long olfactory prodrome that would reliably evolve into an olfactory hallucination and eventually a generalized convulsion $(236,237)$. Medial temporal epileptic discharges during her attacks were confirmed using sphenoidal electrodes. Smelling an unpleasant odor in the early phase of her attacks (such as hydrogen sulfide, dimercaprol or jasmine) would reliably prevent the seizure progressing, and she was able to use this approach for seizure control.

Experimental evidence from the amygdala-kindling model supports olfactory stimulation as a plausible treatment. After rats had been fully kindled, olfactory presentation of toluene was effective at preventing seizures (238). Smelling either toluene or ammonia increased the amygdala stimulation threshold for inducing events, and with ammonia the seizure duration was also decreased.

Conversely, there are rare reports of seizures being triggered by an olfactory stimulus. During depth-electrode recording from the amygdala in an awake patient (239), smelling various odors induced an amygdala discharge accompanied by similar symptoms to her usual focal seizures.

The therapeutic use of an odor to abort seizures is unfortunately only applicable to a very small number of patients. It requires that the patient have a long aura phase with preserved awareness where they can take this action, and the even then, the probability of this intervention being successful is unknown. Nonetheless, it does demonstrate an important mechanism of relevance to more invasive treatment approaches.

\section{DEEP BRAIN STIMULATION OF PIRIFORM CORTEX}

If physiological stimulation of piriform cortex can interrupt or prevent seizures, then perhaps direct electrical stimulation at this site could have the same effect. Deep brain stimulation (DBS) for focal epilepsy in human beings has shown promising results, particularly with stimulation of the anterior nucleus of the thalamus $(240,241)$. However, piriform DBS has not been performed in human beings, and only a few studies have been done in experimental animals.
In rats, low-frequency electrical stimulation of the piriform cortex at $1 \mathrm{~Hz}$ has been used. With an amygdala-kindling model, piriform stimulation inhibits the kindling process (242), and also decreases the incidence of generalized seizures in fully kindled animals. More specifically, this was achieved by stimulation of the ipsilateral central piriform cortex, with contralateral stimulation being less effective $(243,244)$. On the other hand, when the kindling was initially directed at the piriform cortex, inhibitory piriform stimulation was not effective (245). Therefore, piriform stimulation may be most useful when it is a secondary relay for discharges, rather than the primary epileptogenic site, with the aim being to preventing piriform-mediated amplification and distribution of widespread discharges.

Therefore, whether piriform cortex or endopiriform nucleus DBS may be of any benefit in human focal epilepsy is currently unknown. At a minimum, further studies of DBS to these targets in animal models of epilepsy will be needed to approach this question.

\section{CASE REPORT: SURGICAL TREATMENT OF POSSIBLE PIRIFORM EPILEPSY}

Surgical intervention involving the piriform cortex may be beneficial for carefully selected patients, but poses a particular diagnostic and anatomical challenge. Here, we report a 37-year-old woman who had seizures from the second year of life, which consisted of an aura of feeling scared, followed by screaming and wild flailing of all limbs or cycling leg movements. She did not have an olfactory aura. Events were brief, lasting less than $1 \mathrm{~min}$. Ictal scalp EEG showed bitemporal rhythmic delta. High-resolution MRI did not identify any lesion. FDG-PET was non-localizing. One ictal-interictal SPECT suggested right orbitofrontal hyperperfusion.

Video-EEG monitoring was performed with multiple frontal and temporal intracranial electrodes, including a depth-electrode targeting the frontal piriform cortex, placed via the lateral frontal lobe (Figures 4A,B). Inter-ictal recordings showed bursts of epileptiform gamma over the orbitofrontal cortex, and spiking at the hippocampus and temporal pole. Sub-clinical electrographic seizures (Figure 4D) were recorded from the piriform cortex electrode, showing 1-2 min runs of rhythmic sharp waves. Her stereotyped clinical seizures (Figure 4E) showed attenuation and gamma frequencies at the piriform and orbitofrontal electrodes, then an evolving ictal rhythm at these locations and over the right temporal lobe.

A right temporal lobectomy was performed, and was extended into the frontal lobe to remove frontal piriform cortex, along with posterior parts of the inferior frontal gyrus and lateral orbital gyrus. Resection was also extended to remove temporal piriform cortex, the antero-inferior amygdala, and the hippocampus (Figure 4C). Histology of the orbitofrontal tissue showed some disorganized architecture and prominent single white matter neurons, interpreted by the neuropathologist as possible focal cortical dysplasia (MCD 1) although no balloon cells or dysmorphic neurons were seen. No tissue abnormality was found in temporal lobe structures.

Following surgery, she had a marked reduction of seizure frequency, from several events per day to occasional and mainly nocturnal events. There was immediate improvement in her 


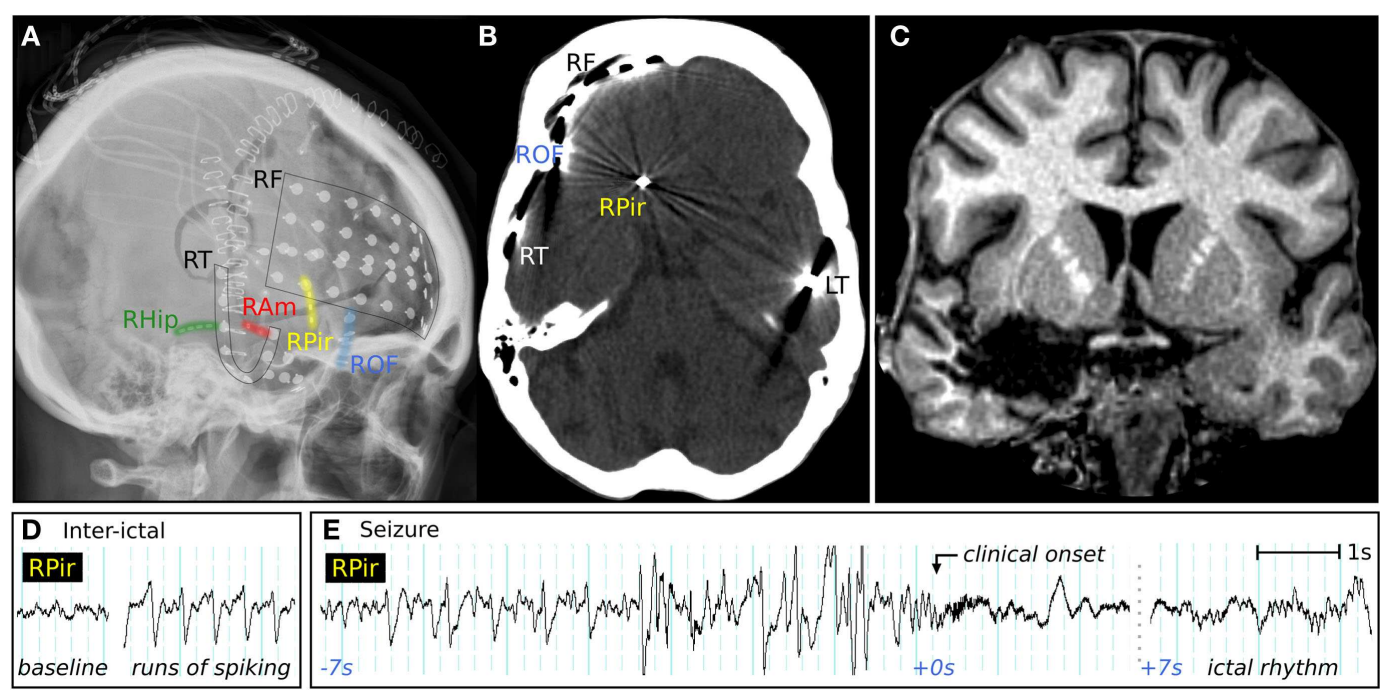

FIGURE 4 | Clinical imaging of a patient with possible piriform epilepsy (A) Lateral skull X-ray showing positions of intracranial electrodes. RF, right frontal subdural electrodes; RT, right temporal subdural electrode strip; RHip, right hippocampal depth electrode; RAm, right amygdala depth electrodes; RPir, right piriform electrodes; ROF, right orbitofrontal subdural electrodes; LT, left temporal subdural electrode strip. (B) CT performed in the piriform axis showing the position of the most inferomesial RPir electrode contact, in orbitofrontal cortex adjacent to frontal piriform cortex. (C) Coronal T1-weighted MRI, showing posterior extent of surgical resection, with removal of right frontal piriform cortex. (D) EEG recorded from most inferomesial RPir electrode, showing trains of inter-ictal spiking, and (E) a seizure from sleep, with progressively building discharges, then gamma activity and attenuation, followed $7 \mathrm{~s}$ later by an evolving ictal rhythm. At the "clinical onset," there was explosive onset of screaming and flailing movements of the limbs. responsiveness and speed of processing compared to her preoperative psychomotor slowness. Although the semiology in this case simultaneously suggested frontal lobe (ictal hypermotor activity) and amygdala activity (prolonged episodes of fear), the implantation identified orbitofrontal cortex or frontal piriform cortex as the most likely regions of onset. Resection of these structures was by necessity incomplete, in part because of the dangerous proximity of the middle cerebral artery and other vessels traversing the anterior perforated substance.

\section{DISCUSSION}

In this review, we have examined several lines of evidence that associate the piriform cortex with focal epilepsy. The central question is therefore, what role does the piriform cortex play?

It is clearly the generator of seizures in animal models where chemical or electrical stimulation is applied directly to the piriform cortex. The human piriform cortex is very likely to share this exquisite sensitivity to pro-convulsive stimulation. However, only very rare cases of human epilepsy arising directly from piriform cortex have been described, such as that of Mizobuchi et al. (118), and arguably the case report described above.

Conversely, the piriform cortex will be an unrelated bystander in some forms of epilepsy, with no role in seizure onset or spread. Focal seizures from the occipital or parietal lobes may be examples in this category, although only limited data about the piriform cortex has been reported for these patients so far $(154,220,225)$.

Of greater clinical relevance, the piriform cortex is a common target of discharge spread, particularly in frontal lobe and temporal lobe epilepsy. This is indicated by the site of lesions that can produce an olfactory epileptic aura (102), the impact of fronto-temporal epilepsy on olfactory function (115), and the detection of piriform cortex activity on EEG-fMRI in these cases (151).

A role for the piriform cortex during human epileptogenesis is probable, but remains to be confirmed. Its tendency to suffer preferential neuronal loss following seizures, as observed in both human status epilepticus (156), and in animal models of induced epilepsy (181), may lead to electrophysiological and local microcircuit changes (185), which result in piriform hyper-excitability. We hypothesize that when the piriform cortex is a target of discharge spread, it can be readily recruited as a secondary hyper-excitable node in the epileptic network by this mechanism. However, inhibition of the piriform cortex only partially blocks the development of epilepsy (86), meaning that it is still possible for epileptogenesis to occur via other less sensitive pathways.

Subsequently the piriform cortex can act as a distributor of epileptic discharges, by facilitating seizures with a limbic origin to spread into olfactory and cortical networks, and vice versa. The evidence for this comes from the amygdala-kindling model of focal epilepsy (3), and clinical descriptions of aura progression (116).

This predisposition of piriform cortex to become involved in focal epilepsy may be understood from the perspective of the architecture that has developed to achieve its normal function. The high inter-connectivity of excitatory neurons provides the basis for a spatially distributed representation of odors, with an intrinsic method for template completion and pattern matching (37). However, this same architecture makes it prone to forming hyper-excitable local networks if local inhibitory circuits are altered or lost. Furthermore, strong reciprocal connectivity to nearby structures such as the olfactory bulb, amygdala, and 
hippocampus-entorhinal cortex are essential for top-down modulation of olfactory inputs, olfactory memory, and the processing of emotional salience. However, these loops pose the risk of becoming reentrant circuits that sustain seizure activity (3).

Therefore the piriform cortex is highly relevant to the understanding of human focal epilepsy arising from the temporal or frontal lobes. It is a common node of discharge spread, can be injured and kindled by seizure activity, and may be involved in the facilitation and distribution of epileptic discharges throughout limbic and cortical networks. It is a potential target for invasive therapies, including EEG recording and surgical resection, and its unique properties and anatomical relationships must be taken into account.

\section{ACKNOWLEDGMENTS}

We thank Prof Matthias Koepp for providing the imaging data for Figure 3A. We acknowledge the work of Dr John Archer, Prof Gavin Fabinyi, and Prof Renate Kalnins in providing the electrophysiology, neurosurgery and histopathological data presented in the case report. This study was supported by the National Health and Medical Research Council of Australia (NHMRC Project Grant 628952, Practitioner Fellowship 1060312 and Postgraduate Scholarship 1055877), and by the Operational Infrastructure Support Program of the State Government of Victoria.

\section{REFERENCES}

1. Haberly LB. Neuronal circuitry in olfactory cortex: anatomy and functional implications. Chem Senses (1985) 10:219-38. doi:10.1093/chemse/10.2.219

2. Haberly LB, Price JL. Association and commissural fiber systems of the olfactory cortex of the rat. I. Systems originating in the piriform cortex and adjacent areas. J Comp Neurol (1978) 178:711-40. doi:10.1002/cne.901780408

3. Löscher W, Ebert U. The role of the piriform cortex in kindling. Prog Neurobiol (1996) 50:427-81. doi:10.1016/S0301-0082(96)00036-6

4. Giessel AJ, Datta SR. Olfactory maps, circuits and computations. Curr Opin Neurobiol (2014) 24:120-32. doi:10.1016/j.conb.2013.09.010

5. Carmichael ST, Clugnet M-C, Price JL. Central olfactory connections in the macaque monkey. J Comp Neurol (1994) 346:403-34. doi:10.1002/cne. 903460306

6. Shipley M, Reyes P. Anatomy of the human olfactory bulb and central olfactory pathways. In: Laing DG, Doty RL, Breipohl W, editors. The Human Sense of Smell. Berlin: Springer (1991). p. 29-60.

7. Mai JK, Paxinos G, Voss T. Atlas of the Human Brain. Amsterdam: Elsevier (2008).

8. Haberly LB. Comparative aspects of olfactory cortex. In: Jones EG, Peters A, editors. Cerebral Cortex. New York, NY: Plenum Press (1990). p. 137-66.

9. Amunts K, Lepage C, Borgeat L, Mohlberg H, Dickscheid T, Rousseau M-É, et al. BigBrain: an ultrahigh-resolution 3d human brain model. Science (2013) 340:1472-5. doi:10.1126/science.1235381

10. Gonçalves Pereira PM, Insausti R, Artacho-Pérula E, Salmenperä T, Kälviäinen R, Pitkänen A. MR volumetric analysis of the piriform cortex and cortical amygdala in drug-refractory temporal lobe epilepsy. AJNR Am J Neuroradiol (2005) 26:319-32. Available from: http://www.ajnr.org/content/26/2/319.long

11. Allison AC. The secondary olfactory areas in the human brain. J Anat (1954) 88:481.

12. Porter J, Anand T, Johnson B, Khan RM, Sobel N. Brain mechanisms for extracting spatial information from smell. Neuron (2005) 47:581-92. doi:10.1016/j. neuron.2005.06.028

13. Royet J-P, Morin-Audebrand L, Cerf-Ducastel B, Haase L, Issanchou S, Murphy $\mathrm{C}$, et al. True and false recognition memories of odors induce distinct neural signatures. Front Hum Neurosci (2011) 5:65. doi:10.3389/fnhum.2011.00065

14. Gottfried JA, Winston JS, Dolan RJ. Dissociable codes of odor quality and odorant structure in human piriform cortex. Neuron (2006) 49:467-79. doi:10.1016/j.neuron.2006.01.007
15. Neville KR, Haberly LB. Olfactory cortex. In: Shepherd GM, editor. The Synaptic Organization of the Brain. Oxford: Oxford University Press (2004). p. 415-71.

16. Price JL. An autoradiographic study of complementary laminar patterns of termination of afferent fibers to the olfactory cortex. J Comp Neurol (1973) 150:87-108. doi:10.1002/cne.901500105

17. Suzuki N, Bekkers JM. Neural coding by two classes of principal cells in the mouse piriform cortex. J Neurosci (2006) 26:11938-47. doi:10.1523/jneurosci. 3473-06.2006

18. Suzuki N, Bekkers JM. Inhibitory neurons in the anterior piriform cortex of the mouse: classification using molecular markers. J Comp Neurol (2010) 518:1670-87. doi:10.1002/cne.22295

19. Young A, Sun Q-Q. GABAergic inhibitory interneurons in the posterior piriform cortex of the GAD67-GFP mouse. Cereb Cortex (2009) 19:3011-29. doi:10.1093/cercor/bhp072

20. Franks KM, Russo MJ, Sosulski DL, Mulligan AA, Siegelbaum SA, Axel R. Recurrent circuitry dynamically shapes the activation of piriform cortex. Neuron (2011) 72:49-56. doi:10.1016/j.neuron.2011.08.020

21. Luna VM, Schoppa NE. GABAergic circuits control input-spike coupling in the piriform cortex. J Neurosci (2008) 28:8851-9. doi:10.1523/jneurosci.2385-08. 2008

22. Stokes CCA, Isaacson JS. From dendrite to soma: dynamic routing of inhibition by complementary interneuron microcircuits in olfactory cortex. Neuron (2010) 67:452-65. doi:10.1016/j.neuron.2010.06.029

23. Suzuki N, Bekkers JM. Microcircuits mediating feedforward and feedback synaptic inhibition in the piriform cortex. J Neurosci (2012) 32:919-31. doi:10.1523/jneurosci.4112-11.2012

24. Behan M, Haberly LB. Intrinsic and efferent connections of the endopiriform nucleus in rat. J Comp Neurol (1999) 408:532-48. doi:10.1002/(SICI)10969861(19990614)408:4<532::AID-CNE7>3.3.CO;2-J

25. Ekstrand JJ, Domroese ME, Johnson DM, Feig SL, Knodel SM, Behan M, et al. A new subdivision of anterior piriform cortex and associated deep nucleus with novel features of interest for olfaction and epilepsy. J Comp Neurol (2001) 434:289-307. doi:10.1002/cne.1178

26. Sugai T, Yamamoto R, Yoshimura H, Kato N. Multimodal cross-talk of olfactory and gustatory information in the endopiriform nucleus in rats. Chem Senses (2012) 37:681-8. doi:10.1093/chemse/bjs046

27. Kowianski P, Dziewiatkowski J, Kowianska J, Morys J. Comparative anatomy of the claustrum in selected species: a morphometric analysis. Brain Behav Evol (1999) 53:44-54. doi:10.1159/000006581

28. Crick FC, Koch C. What is the function of the claustrum? Philos Trans R Soc Lond B Biol Sci (2005) 360:1271-9. doi:10.1098/rstb.2005.1661

29. Zhang X, Hannesson D, Saucier D, Wallace A, Howland J, Corcoran M. Susceptibility to kindling and neuronal connections of the anterior claustrum. $J \mathrm{Neu}$ rosci (2001) 21:3674-87. Available from: http://www.jneurosci.org/content/21/ 10/3674.long

30. Shepherd GM. The microcircuit concept applied to cortical evolution: from three-layer to six-layer cortex. Front Neuroanat (2011) 5:30. doi:10.3389/fnana. 2011.00030

31. Ghosh S, Larson SD, Hefzi H, Marnoy Z, Cutforth T, Dokka K, et al. Sensory maps in the olfactory cortex defined by long-range viral tracing of single neurons. Nature (2011) 472:217-20. doi:10.1038/nature09945

32. Ojima H, Mori K, Kishi K. The trajectory of mitral cell axons in the rabbit olfactory cortex revealed by intracellular HRP injection. J Comp Neurol (1984) 230:77-87. doi:10.1002/cne.902300107

33. Davison IG, Ehlers MD. Neural circuit mechanisms for pattern detection and feature combination in olfactory cortex. Neuron (2011) 70:82-94. doi:10.1016/ j.neuron.2011.02.047

34. Wilson DA. Binaral interactions in the rat piriform cortex. J Neurophysiol (1997) 78:160-9.

35. Bouret S, Sara SJ. Locus coeruleus activation modulates firing rate and temporal organization of odour-induced single-cell responses in rat piriform cortex. Eur J Neurosci (2002) 16:2371-82. doi:10.1046/j.1460-9568.2002.02413.x

36. Johnson DM, Illig KR, Behan M, Haberly LB. New features of connectivity in piriform cortex visualized by intracellular injection of pyramidal cells suggest that "primary" olfactory cortex functions like "association" cortex in other sensory systems. J Neurosci (2000) 20:6974-82. Available from: http://www.jneurosci.org/content/20/18/6974.long 
37. Ambros-Ingerson J, Granger R, Lynch G. Simulation of paleocortex performs hierarchical clustering. Science (1990) 247:1344-8. doi:10.1126/science. 2315702

38. Barnes DC, Hofacer RD, Zaman AR, Rennaker RL, Wilson DA. Olfactory perceptual stability and discrimination. Nat Neurosci (2008) 11:1378-80. doi:10.1038/nn.2217

39. Shipley MT, Ennis M. Functional organization of olfactory system. J Neurobiol (1996) 30:123-76. doi:10.1002/(SICI)1097-4695(199605)30:1<123::AIDNEU11>3.3.CO;2-S

40. Kajiwara R, Tominaga T, Takashima I. Olfactory information converges in the amygdaloid cortex via the piriform and entorhinal cortices: observations in the guinea pig isolated whole-brain preparation. Eur J Neurosci (2007) 25:3648-58. doi:10.1111/j.1460-9568.2007.05610.x

41. Krettek JE, Price JL. Projections from the amygdaloid complex and adjacent olfactory structures to the entorhinal cortex and to the subiculum in the rat and cat. J Comp Neurol (1977) 172:723-52. doi:10.1002/cne.901720409

42. Kuroda M, Murakami K, Kishi K, Price JL. Distribution of the piriform corticalterminals to cells in the central segment of the mediodorsal thalamic nucleus of the rat. Brain Res (1992) 595:159-63. doi:10.1016/0006-8993(92)91468-T

43. Russchen FT, Amaral DG, Price JL. The afferent input to the magnocellular division of the mediodorsal thalamic nucleus in the monkey, Macaca fascicularis. J Comp Neurol (1987) 256:175-210. doi:10.1002/cne.902560202

44. Price JL, Slotnick BM, Revial MF. Olfactory projections to the hypothalamus. J Comp Neurol (1991) 306:447-61. doi:10.1002/cne.903060309

45. Kay LM, Sherman SM. An argument for an olfactory thalamus. Trends Neurosci (2007) 30:47-53. doi:10.1016/j.tins.2006.11.007

46. Ramsdell JS, Gulland FM. Domoic acid epileptic disease. Mar Drugs (2014) 12:1185-207. doi:10.3390/md12031185

47. Savic I, Gulyas B, Larsson M, Roland P. Olfactory functions are mediated by parallel and hierarchical processing. Neuron (2000) 26:735-45. doi:10.1016/ S0896-6273(00)81209-X

48. Gottfried JA. Central mechanisms of odour object perception. Nat Rev Neurosci (2010) 11:628-41. doi:10.1038/nrn2883

49. Howard JD, Plailly J, Grueschow M, Haynes J-D, Gottfried JA. Odor quality coding and categorization in human posterior piriform cortex. Nat Neurosci (2009) 12:932-8. doi:10.1038/nn.2324

50. Zelano C, Montag J, Khan R, Sobel N. A specialized odor memory buffer in primary olfactory cortex. PLoS One (2009) 4:e4969. doi:10.1371/journal.pone. 0004965

51. Nigri A, Ferraro S, D’Incerti L, Critchley HD, Bruzzone MG, Minati L. Connectivity of the amygdala, piriform, and orbitofrontal cortex during olfactory stimulation: a functional MRI study. Neuroreport (2013) 24:171-5. doi:10.1097/WNR.0b013e32835d5d2b

52. Illig KR, Haberly LB. Odor-evoked activity is spatially distributed in piriform cortex. J Comp Neurol (2003) 457:361-73. doi:10.1002/cne.10557

53. Stettler DD, Axel R. Representations of odor in the piriform cortex. Neuron (2009) 63:854-64. doi:10.1016/j.neuron.2009.09.005

54. Litaudon P, Amat C, Bertrand B, Vigouroux M, Buonviso N. Piriform cortex functional heterogeneity revealed by cellular responses to odours. Eur J Neurosci (2003) 17:2457-61. doi:10.1046/j.1460-9568.2003.02654.x

55. Mainland J. The sniff is part of the olfactory percept. Chem Senses (2005) 31:181-96. doi:10.1093/chemse/bjj012

56. Rennaker RL, Chen C-FF, Ruyle AM, Sloan AM, Wilson DA. Spatial and temporal distribution of odorant-evoked activity in the piriform cortex. JNeurosci (2007) 27:1534-42. doi:10.1523/jneurosci.4072-06.2007

57. Bensafi M, Sobel N, Khan RM. Hedonic-specific activity in piriform cortex during odor imagery mimics that during odor perception. J Neurophysiol (2007) 98:3254-62. doi:10.1152/jn.00349.2007

58. González J, Barros-Loscertales A, Pulvermüller F, Meseguer V, Sanjuán A, Belloch $\mathrm{V}$, et al. Reading cinnamon activates olfactory brain regions. Neuroimage (2006) 32:906-12. doi:10.1016/j.neuroimage.2006.03.037

59. Gottfried JA, Smith APR, Rugg MD, Dolan RJ. Remembrance of odors past: human olfactory cortex in cross-modal recognition memory. Neuron (2004) 42:687-95. doi:10.1016/S0896-6273(04)00270-3

60. Veldhuizen MG, Small DM. Modality-specific neural effects of selective attention to taste and odor. Chem Senses (2011) 36:747-60. doi:10.1093/chemse/ bjr043
61. Gottfried JA, Zelano C. The value of identity: olfactory notes on orbitofrontal cortex function: olfactory perspectives on OFC function. Ann N Y Acad Sci (2011) 1239:138-48. doi:10.1111/j.1749-6632.2011.06268.x

62. Kringelbach ML, Rolls ET. The functional neuroanatomy of the human orbitofrontal cortex: evidence from neuroimaging and neuropsychology. Prog Neurobiol (2004) 72:341-72. doi:10.1016/j.pneurobio.2004.03.006

63. Zelano C, Mohanty A, Gottfried JA. Olfactory predictive codes and stimulus templates in piriform cortex. Neuron (2011) 72:178-87. doi:10.1016/j.neuron. 2011.08.010

64. Tham WWP, Stevenson RJ, Miller LA. The role of the mediodorsal thalamic nucleus in human olfaction. Neurocase (2011) 17:148-59. doi:10.1080/ 13554794.2010.504728

65. Cohen Y, Wilson DA, Barkai E. Differential modifications of synaptic weights during odor rule learning: dynamics of interaction between the piriform cortex with lower and higher brain areas. Cereb Cortex (2013). doi:10.1093/cercor/ bht 215

66. Plailly J, Howard JD, Gitelman DR, Gottfried JA. Attention to odor modulates thalamocortical connectivity in the human brain. J Neurosci (2008) 28:5257-67. doi:10.1523/JNEUROSCI.5607-07.2008

67. Chu S, Downes JJ. Odour-evoked autobiographical memories: psychological investigations of proustian phenomena. Chem Senses (2000) 25:111-6. doi:10.1093/chemse/25.1.111

68. Kjelvik G, Evensmoen HR, Brezova V, Håberg AK. The human brain representation of odor identification. J Neurophysiol (2012) 108:645-57. doi:10.1152/ jn.01036.2010

69. Royet J-P, Plailly J, Delon-Martin C, Kareken DA, Segebarth C. fMRI of emotional responses to odors. Neuroimage (2003) 20:713-28. doi:10.1016/S10538119(03)00388-4

70. Winston JS. Integrated neural representations of odor intensity and affective valence in human amygdala. J Neurosci (2005) 25:8903-7. doi:10.1523/ jneurosci.1569-05.2005

71. Savic I, Berglund H. Passive perception of odors and semantic circuits. Hum Brain Mapp (2004) 21:271-8. doi:10.1002/hbm.20009

72. Olofsson JK, Rogalski E, Harrison T, Mesulam M-M, Gottfried JA. A cortical pathway to olfactory naming: evidence from primary progressive aphasia. Brain (2013) 136:1245-59. doi:10.1093/brain/awt019

73. Piredda S, Gale K. A crucial epileptogenic site in the deep prepiriform cortex. Nature (1985) 317:623-5. doi:10.1038/317623a0

74. Gale K. Progression and generalization of seizure discharge: anatomical and neurochemical substrates. Epilepsia (1988) 29:S15-34. doi:10.1111/j.15281157.1988.tb05795.x

75. Piredda S, Gale K. Role of excitatory amino acid transmission in the genesis of seizures elicited from the deep prepiriform cortex. Brain Res (1986) 377:205-10. doi:10.1016/0006-8993(86)90859-0

76. Tortorella A, Halonen T, Sahibzada N, Gale K. A crucial role of the $\alpha$-amino3-hydroxy-5-methylisoxazole-4-propionic acid subtype of glutamate receptors in piriform and perirhinal cortex for the initiation and propagation of limbic motor seizures. J Pharmacol Exp Ther (1997) 280:1401-5.

77. Ebert U, Wlaź P, Löscher W. High susceptibility of the anterior and posterior piriform cortex to induction of convulsions by bicuculline. Eur J Neurosci (2000) 12:4195-205. doi:10.1111/j.1460-9568.2000.01315.x

78. Gale K. Chemoconvulsant seizures: advantages of focally-evoked seizure models. Ital J Neurol Sci (1995) 16:17-25. doi:10.1007/BF02229070

79. Gale K, Dubach M. Localization of area tempestas in the piriform cortex of the monkey. In: AES proceedings. Annual meeting of the American Epilepsy Society, Miami, Florida. Epilepsia (1993) 34(Suppl 6):21.

80. Halonen T, Tortorella A, Zrebeet H, Gale K. Posterior piriform and perirhinal cortex relay seizures evoked from the area tempestas: role of excitatory and inhibitory amino acid receptors. Brain Res (1994) 652:145-8. doi:10.1016/0006-8993(94)90328-X

81. Cassidy RM, Gale K. Mediodorsal thalamus plays a critical role in the development of limbic motor seizures. J Neurosci (1998) 18:9002-9.

82. Eells JB, Clough RW, Browning RA, Jobe PC. Comparative fos immunoreactivity in the brain after forebrain, brainstem, or combined seizures induced by electroshock, pentylenetetrazol, focally induced and audiogenic seizures in rats. Neuroscience (2004) 123:279-92. doi:10.1016/j.neuroscience. 2003.08.015 
83. Lanaud P, Maggio R, Gale K, Grayson DR. Temporal and spatial patterns of expression of c-fos, zif/268, c-Jun and Jun-B mRNAs in rat brain following seizures evoked focally from the deep prepiriform cortex. Exp Neurol (1993) 119:20-31. doi:10.1006/exnr.1993.1003

84. Maggio R, Lanaud P, Grayson DR, Gale K. Expression of c-fos mRNA following seizures evoked from an epileptogenic site in the deep prepiriform cortex: regional distribution in brain as shown by in situ hybridization. Exp Neurol (1993) 119:11-9. doi:10.1006/exnr.1993.1002

85. Demir R, Haberly LB, Jackson MB. Epileptiform discharges with in-vivo-like features in slices of rat piriform cortex with longitudinal association fibers. J Neurophysiol (2001) 86:2445-60. Available from: http://jn.physiology.org/ content/86/5/2445.long

86. Morimoto K, Fahnestock M, Racine RJ. Kindling and status epilepticus models of epilepsy: rewiring the brain. Prog Neurobiol (2004) 73:1-60. doi:10.1016/j. pneurobio.2004.03.009

87. Mohapel P, Zhang X, Gillespie G, Chlan-Fourney J, Hannesson D, Corley S, et al. Kindling of the claustrum and insular cortex: comparison to perirhinal cortex in the rat. Eur J Neurosci (2001) 13:1501-19. doi:10.1046/j.0953-816x. 2001.01532.x

88. McIntyre DC, Gilby KL. Mapping seizure pathways in the temporal lobe. Epilepsia (2008) 49(Suppl 3):23-30. doi:10.1111/j.1528-1167.2008.01507.x

89. Honack D, Wahnschaffe U, Loscher W. Kindling from stimulation of a highly sensitive locus in the posterior part of the piriform cortex. Comparison with amygdala kindling and effects of antiepileptic drugs. Brain Res (1991) 538:196-202. doi:10.1016/0006-8993(91)90430-4

90. Löscher W, Ebert U, Wahnschaffe U, Rundfeldt C. Susceptibility of different cell layers of the anterior and posterior part of the piriform cortex to electrical stimulation and kindling: comparison with the basolateral amygdala and "area tempestas”. Neuroscience (1995) 66:265-76. doi:10.1016/0306-4522(94)00614-B

91. Cain DP, Corcoran ME, Desborough KA, McKitrick DJ. Kindling in the deep prepyriform cortex of the rat. Exp Neurol (1988) 100:203-9. doi:10.1016/00144886(88)90212-9

92. Morimoto K, Dragunow M, Goddard GV. Deep prepyriform cortex kindling and its relation to amygdala kindling in the rat. Exp Neurol (1986) 94:637-48. doi:10.1016/0014-4886(86)90243-8

93. Inoue K, Morimoto K, Sato K, Yamada N, Otsuki S. Mechanisms in the development of limbic status epilepticus and hippocampal neuron loss: an experimental study in a model of status epilepticus induced by kindling-like electrical stimulation of the deep prepyriform cortex in rats. Acta Med Okayama (1992) 46:129-39.

94. White LE, Price JL. The functional anatomy of limbic status epilepticus in the rat. I. Patterns of 14C-2-deoxyglucose uptake and Fos immunocytochemistry. J Neurosci (1993) 13:4787-809.

95. Chapman A, Racine RJ. Piriform cortex efferents to the entorhinal cortex in vivo: kindling-induced potentiation and the enhancement of long-term potentiation by low-frequency piriform cortex or medial septal stimulation. Hippocampus (1997) 7:257-70. doi:10.1002/(SICI)1098-1063(1997)7:3<257: AID-HIPO2>3.0.CO;2-I

96. Elliott B, Joyce E, Shorvon S. Delusions, illusions and hallucinations in epilepsy: 1. Elementary phenomena. Epilepsy Res (2009) 85:162-71. doi:10. 1016/j.eplepsyres.2009.03.018

97. Jacek S, Stevenson RJ, Miller LA. Olfactory dysfunction in temporal lobe epilepsy: a case of ictus-related parosmia. Epilepsy Behav (2007) 11:466-70. doi:10.1016/j.yebeh.2007.05.016

98. Daly D. Uncinate fits. Neurology (1958) 8:250-250. doi:10.1212/WNL.8.4.250

99. Jackson JH, Beevor CE. Case of tumour of the right temporosphenoidal lobe bearing on the localisation of the sense of smell and on the interpretation of a particular variety of epilepsy. Brain (1889) 12:346-9. doi:10.1093/brain/ 12.3.346

100. Jackson JH, Stewart P. Epileptic attacks with a warning of a crude sensation of smell and with the intellectual aura (dreamy state) in a patient who had symptoms pointing to gross organic disease of the right temporo-sphenoidal lobe. Brain (1899) 22:534-49. doi:10.1093/brain/22.4.534

101. Mills CK. The cerebral centers for taste and smell and the uncinate group of fits, based on the study of a case of tumor of the temporal lobe with necropsy. J Am Med Assoc (1908) LI:879-85. doi:10.1001/jama.1908.25410110001001

102. Acharya V, Acharya J, Lüders H. Olfactory epileptic auras. Neurology (1998) 51:56-61. doi:10.1212/WNL.51.1.56
103. Howe JG, Gibson JD. Uncinate seizures and tumors, a myth reexamined. Ann Neurol (1982) 12:227-227. doi:10.1002/ana.410120238

104. Lennox WG, Cobb S. Epilepsy: XIII. Aura in epilepsy; a statistical review of 1,359 cases. Arch Neurol Psychiatry (1933) 30:374-87. doi:10.1001/archneurpsyc. 1933.02240140138007

105. Manford M, Fish DR, Shorvon SD. An analysis of clinical seizure patterns and their localizing value in frontal and temporal lobe epilepsies. Brain (1996) 119:17-40. doi:10.1093/brain/119.1.17

106. Mauguière F. Scope and presumed mechanisms of hallucinations in partial epileptic seizures. Epileptic Disord (1999) 1:81-91.

107. Ye BS, Cho Y-J, Jang SH, Lee MK, Lee BI, Heo K. The localizing and lateralizing value of auras in lesional partial epilepsy patients. Yonsei Med J (2012) 53:477-85. doi:10.3349/ymj.2012.53.3.477

108. Arseni C, Petrovici IN. Epilepsy in temporal lobe tumours. Eur Neurol (1971) 5:201-14. doi:10.1159/000114072

109. Binder DK, Garcia PA, Elangovan GK, Barbaro NM. Characteristics of auras in patients undergoing temporal lobectomy: clinical article. J Neurosurg (2009) 111:1283-9. doi:10.3171/2009.3.JNS081366

110. Chen C, Shih Y-H, Yen D-J, Lirng J-F, Guo Y-C, Yu H-Y, et al. Olfactory auras in patients with temporal lobe epilepsy. Epilepsia (2003) 44:257-60. doi:10.1046/j.1528-1157.2003.25902.x

111. Gupta AK, Jeavons PM, Hughes RC, Covanis A. Aura in temporal lobe epilepsy: clinical and electroencephalographic correlation. J Neurol Neurosurg Psychiatry (1983) 46:1079-83. doi:10.1136/jnnp.46.12.1079

112. Mulder DW, Daly D. Psychiatric symptoms associated with lesions of temporal lobe. J Am Med Assoc (1952) 150:173-6. doi:10.1001/jama.1952. 03680030005003

113. Penfield W, Perot P. The brain's record of auditory and visual experience. A final summary and discussion. Brain (1963) 86:595-696. doi:10.1093/brain/ 86.4.595

114. Fried I, Spencer DD, Spencer SS. The anatomy of epileptic auras: focal pathology and surgical outcome. J Neurosurg (1995) 83:60-6. doi:10.3171/jns.1995. 83.1.0060

115. West SE, Doty RL. Influence of epilepsy and temporal lobe resection on olfactory function. Epilepsia (1995) 36:531-42. doi:10.1111/j.1528-1157.1995. tb02565.x

116. Widdess-Walsh P, Kotagal P, Jeha L, Wu G, Burgess R. Multiple auras: clinical significance and pathophysiology. Neurology (2007) 69:755-61. doi:10.1212/ 01.wnl.0000267650.50269.5d

117. Kasper BS, Kasper EM, Pauli E, Stefan H. Phenomenology of hallucinations, illusions, and delusions as part of seizure semiology. Epilepsy Behav (2010) 18:13-23. doi:10.1016/j.yebeh.2010.03.006

118. Mizobuchi M, Ito N, Tanaka C, Sako K, Sumi Y, Sasaki T. Unidirectional olfactory hallucination associated with ipsilateral unruptured intracranial aneurysm. Epilepsia (1999) 40:516-9. doi:10.1111/j.1528-1157.1999.tb00751.x

119. Geyer JD, Payne TA, Faught E, Drury I. Postictal nose-rubbing in the diagnosis, lateralization, and localization of seizures. Neurology (1999) 52:743-743. doi:10.1212/WNL.52.4.743

120. Weil AA. Depressive reactions associated with temporal lobe-uncinate seizures. J Nerv Ment Dis (1955) 121:505-10. doi:10.1097/00005053195506000-00002

121. Van Paesschen W, King MD, Duncan JS, Connelly A. The amygdala and temporal lobe simple partial seizures: a prospective and quantitative MRI study. Epilepsia (2001) 42:857-62. doi:10.1046/j.1528-1157.2001.042007857.x

122. Nye E, Arendts G. Intracerebral haemorrhage presenting as olfactory hallucinations. Emerg Med (2002) 14:447-9. doi:10.1046/j.1442-2026.2002.00385.x

123. Andy OJ, Jurko MF, Hughes JR. The amygdala in relation to olfaction. Confin Neurol (1975) 37:215-22. doi:10.1159/000102743

124. Lehrner J, Baumgartner C, Serles W, Olbrich A, Pataraia E, Bacher J, et al. Olfactory prodromal symptoms and unilateral olfactory dysfunction are associated in patients with right mesial temporal lobe epilepsy. Epilepsia (1997) 38:1042-4. doi:10.1111/j.1528-1157.1997.tb01490.x

125. Hirsch LJ, Lain AH, Walczak TS. Postictal nosewiping lateralizes and localizes to the ipsilateral temporal lobe. Epilepsia (1998) 39:991-7. doi:10.1111/j.15281157.1998.tb01449.x

126. Leutmezer F, Serles W, Lehrner J, Pataraia E, Zeiler K, Baumgartner C. Postictal nose wiping: a lateralizing sign in temporal lobe complex partial seizures. Neurology (1998) 51:1175-7. doi:10.1212/WNL.51.4.1175 
127. Wennberg R. Postictal coughing and noserubbing coexist in temporal lobe epilepsy. Neurology (2001) 56:133-4. doi:10.1212/WNL.56.1.133-a

128. Meletti S, Cantalupo G, Stanzani-Maserati M, Rubboli G, Alberto Tassinari C. The expression of interictal, preictal, and postictal facial-wiping behavior in temporal lobe epilepsy: a neuro-ethological analysis and interpretation. Epilepsy Behav (2003) 4:635-43. doi:10.1016/j.yebeh.2003.09.004

129. Wennberg R. Electroclinical analysis of postictal noserubbing. Can J Neurol Sci (2000) 27:131-6. Available from: http://cjns.metapress.com/content/ yjr532r895nwlayy/fulltext.pdf

130. Catenoix H, Guenot M, Isnard J, Fischer C, Mauguiere F, Ryvlin P. Intracranial EEG study of seizure-associated nose wiping. Neurology (2004) 63:1127-9. doi:10.1212/01.WNL.0000138573.62251.59

131. Baars BJ. Multiple sources of conscious odor integration and propagation in olfactory cortex. Front Psychol (2013) 4:930. doi:10.3389/fpsyg.2013.00930

132. Keller A. Attention and olfactory consciousness. Front Psychol (2011) 2:380. doi:10.3389/fpsyg.2011.00380

133. Bancaud J, Talairach J. Clinical semiology of frontal lobe seizures. Adv Neurol (1992) 57:3-58.

134. Kotagal P, Arunkumar G, Hammel J, Mascha E. Complex partial seizures of frontal lobe onset statistical analysis of ictal semiology. Seizure (2003) 12:268-81. doi:10.1016/S1059-1311(02)00276-5

135. Ludwig BI, Marsan CA, Van Buren J. Depth and direct cortical recording in seizure disorders of extratemporal origin. Neurology (1976) 26:1085-1085. doi:10.1212/WNL.26.11.1085

136. Schneider RC, Crosby EC, Bagchi BK, Calhoun HD. Temporal or occipital lobe hallucinations triggered from frontal lobe lesions. Neurology (1961) 11:172-172. doi:10.1212/WNL.11.2.172

137. Kumar G, Juhász C, Sood S, Asano E. Olfactory hallucinations elicited by electrical stimulation via subdural electrodes: effects of direct stimulation of olfactory bulb and tract. Epilepsy Behav (2012) 24:264-8. doi:10.1016/j.yebeh.2012. 03.027

138. King DW, Marsan CA. Clinical features and ictal patterns in epileptic patients with EEG temporal lobe foci. Ann Neurol (1977) 2:138-47. doi:10.1002/ana. 410020209

139. Wieser HG. Depth recorded limbic seizures and psychopathology. Neurosci Biobehav Rev (1983) 7:427-40. doi:10.1016/0149-7634(83)90050-7

140. Gil-Nagel A, Risinger MW. Ictal semiology in hippocampal versus extrahippocampal temporal lobe epilepsy. Brain (1997) 120:183-92. doi:10.1093/brain/ 120.1.183

141. Bancaud J, Brunet-Bourgin F, Chauvel P, Halgren E. Anatomical origin of déjà vu and vivid "memories" in human temporal lobe epilepsy. Brain (1994) 117:71-90. doi:10.1093/brain/117.1.71

142. Munari C, Bancaud J. Electroclinical symptomatology of partial seizures of orbital frontal origin. Adv Neurol (1992) 57:257-65.

143. Greenberg MS. Olfactory hallucinations. In: Serby MH, Chobor KL, editors. Science of Olfaction. New York, NY: Springer-Verlag (1992). p. 467-99.

144. Penfield W, Jasper HH. Epilepsy and The Functional Anatomy of The Human Brain. Boston: Little, Brown \& Co (1954).

145. Van Buren JM. Sensory, motor and autonomic effects of mesial temporal stimulation in man. J Neurosurg (1961) 18:273-88. doi:10.3171/jns.1961.18. 3.0273

146. Bartolomei F, Barbeau E, Gavaret M, Guye M, McGonigal A, Régis J, et al. Cortical stimulation study of the role of rhinal cortex in déjà vu and reminiscence of memories. Neurology (2004) 63:858-64. doi:10.1212/01.WNL.0000137037. $56916.3 \mathrm{~F}$

147. Fish DR, Gloor P, Quesney FL, Oliver A. Clinical responses to electrical brain stimulation of the temporal and frontal lobes in patients with epilepsy Pathophysiological implications. Brain (1993) 116:397-414. doi:10. 1093/brain/116.2.397

148. Gloor P, Olivier A, Quesney LF, Andermann F, Horowitz S. The role of the limbic system in experiential phenomena of temporal lobe epilepsy. Ann Neurol (1982) 12:129-44. doi:10.1002/ana.410120203

149. Vaudano AE, Carmichael DW, Salek-Haddadi A, Rampp S, Stefan H, Lemieux $\mathrm{L}$, et al. Networks involved in seizure initiation. A reading epilepsy case studied with EEG-fMRI and MEG. Neurology (2012) 79:249-53. doi:10.1212/WNL. 0b013e31825fdf3a

150. Salek-Haddadi A, Mayer T, Hamandi K, Symms M, Josephs O, Fluegel D, et al. Imaging seizure activity: a combined EEG/EMG-fMRI study in reading epilepsy. Epilepsia (2009) 50:256-64. doi:10.1111/j.1528-1167.2008.01737.x
151. Laufs H, Richardson MP, Salek-Haddadi A, Vollmar C, Duncan JS, Gale $\mathrm{K}$, et al. Converging PET and fMRI evidence for a common area involved in human focal epilepsies. Neurology (2011) 77:904-10. doi:10.1212/WNL. 0b013e31822c90f2

152. Koubeissi M, Bartolomei F, Abdelrahman B, Picard F. Electrical stimulation of a small brain area reversibly disrupts consciousness. Epilepsy Behav (2014) 37:32-5. doi:10.1016/j.yebeh.2014.05.027

153. Flanagan D, Badawy RAB, Jackson GD. EEG-fMRI in focal epilepsy: local activation and regional networks. Clin Neurophysiol (2014) 125:21-31. doi:10. 1016/j.clinph.2013.06.182

154. Fahoum F, Lopes R, Pittau F, Dubeau F, Gotman J. Widespread epileptic networks in focal epilepsies: EEG-fMRI study. Epilepsia (2012) 53:1618-27. doi:10.1111/j.1528-1167.2012.03533.x

155. Kobayashi E, Grova C, Tyvaert L, Dubeau F, Gotman J. Structures involved at the time of temporal lobe spikes revealed by interindividual group analysis of EEG/fMRI data. Epilepsia (2009) 50:2549-56. doi:10.1111/j.1528-1167.2009. 02180.x

156. Fujikawa DG, Itabashi HH, Wu A, Shinmei SS. Status epilepticus-induced neuronal loss in humans without systemic complications or epilepsy. Epilepsia (2000) 41:981-91. doi:10.1111/j.1528-1157.2000.tb00283.x

157. Cendes F, Andermann F, Carpenter S, Zatorre RJ, Cashman NR. Temporal lobe epilepsy caused by domoic acid intoxication: evidence for glutamate receptor-mediated excitotoxicity in humans. Ann Neurol (1995) 37:123-6. doi:10.1002/ana.410370125

158. Teitelbaum JS, Zatorre RJ, Carpenter S, Gendron D, Evans AC, Gjedde A, et al. Neurologic sequelae of domoic acid intoxication due to the ingestion of contaminated mussels. N Engl J Med (1990) 322:1781-7. doi:10.1056/ NEJM199006213222505

159. Pulido OM. Domoic acid toxicologic pathology: a review. Mar Drugs (2008) 6:180-219. doi:10.3390/md20080010

160. Tiedeken JA, Muha N, Ramsdell JS. A Cupric silver histochemical analysis of domoic acid damage to olfactory pathways following status epilepticus in a rat model for chronic recurrent spontaneous seizures and aggressive behavior. Toxicol Pathol (2013) 41:454-69. doi:10.1177/0192623312453521

161. Curia G, Longo D, Biagini G, Jones RSG, Avoli M. The pilocarpine model of temporal lobe epilepsy. J Neurosci Methods (2008) 172:143-57. doi:10.1016/j. jneumeth.2008.04.019

162. Scorza FA, Arida RM, Naffah-Mazzacoratti Mda G, Scerni DA, Calderazzo L, Cavalheiro EA. The pilocarpine model of epilepsy: what have we learned? An Acad Bras Cienc (2009) 81:345-65. doi:10.1590/S0001-37652009000300003

163. André V, Dubé C, François J, Leroy C, Rigoulot M-A, Roch C, et al. Pathogenesis and pharmacology of epilepsy in the lithium-pilocarpine model. Epilepsia (2007) 48:41-7. doi:10.1111/j.1528-1167.2007.01288.x

164. Wall CJ, Kendall EJ, Obenaus A. Rapid alterations in diffusion-weighted images with anatomic correlates in a rodent model of status epilepticus. AJNR Am J Neuroradiol (2000) 21:1841-52. Available from: http://www.ajnr.org/content/ 21/10/1841.long

165. Roch C, Leroy C, Nehlig A, Namer IJ. Magnetic resonance imaging in the study of the lithium-pilocarpine model of temporal lobe epilepsy in adult rats. Epilepsia (2002) 43:325-35. doi:10.1046/j.1528-1157.2002.11301.x

166. Sinel'nikova VV, Shubina LV, Gol'tyaev MV, Loseva EV, Kichigina VF. Detection of c-fos expression in the brains of animals with a pilocarpine model of temporal lobe epilepsy. Neurosci Behav Physiol (2013) 43:1084-91. doi:10.1007/ s11055-013-9853-6

167. Peredery O, Persinger MA, Parker G, Mastrosov L. Temporal changes in neuronal dropout following inductions of lithium/pilocarpine seizures in the rat. Brain Res (2000) 881:9-17. doi:10.1016/S0006-8993(00)02730-X

168. Druga R, Kubova H, Suchomelova L, Haugvicova R. Lithium/pilocarpine status epilepticus-induced neuropathology of piriform cortex and adjoining structures in rats is age-dependent. Physiol Res (2003) 52:251-64. Available from: http://www.biomed.cas.cz/physiolres/pdf/52/52_251.pdf

169. Chen S, Kobayashi M, Honda Y, Kakuta S, Sato F, Kishi K. Preferential neuron loss in the rat piriform cortex following pilocarpine-induced status epilepticus. Epilepsy Res (2007) 74:1-18. doi:10.1016/j.eplepsyres.2006.11.008

170. de Almeida L, Idiart M, Linster C. A model of cholinergic modulation in olfactory bulb and piriform cortex. J Neurophysiol (2013) 109:1360-77. doi:10.1152/jn.00577.2012

171. Whalley BJ, Postlethwaite M, Constanti A. Further characterization of muscarinic agonist-induced epileptiform bursting activity in immature rat piriform 
cortex, in vitro. Neuroscience (2005) 134:549-66. doi:10.1016/j.neuroscience. 2005.04.018

172. McDonough JH, Shih T-M. Neuropharmacological mechanisms of nerve agent-induced seizure and neuropathology. Neurosci Biobehav Rev (1997) 21:559-79. doi:10.1016/S0149-7634(96)00050-4

173. Fabene PF, Merigo F, Galiè M, Benati D, Bernardi P, Farace P, et al. Pilocarpineinduced status epilepticus in rats involves ischemic and excitotoxic mechanisms. PLoS One (2007) 2:e1105. doi:10.1371/journal.pone.0001105

174. Covolan L, Mello LEAM. Temporal profile of neuronal injury following pilocarpine or kainic acid-induced status epilepticus. Epilepsy Res (2000) 39:133-52. doi:10.1016/S0920-1211(99)00119-9

175. Candelario-Jalil E, Al-Dalain SM, Castillo R, Martínez G, León Fernández OS. Selective vulnerability to kainate-induced oxidative damage in different rat brain regions. J Appl Toxicol (2001) 21:403-7. doi:10.1002/jat.768

176. Chen S, Buckmaster PS. Stereological analysis of forebrain regions in kainatetreated epileptic rats. Brain Res (2005) 1057:141-52. doi:10.1016/j.brainres. 2005.07.058

177. Freichel C, Potschka H, Ebert U, Brandt C, Löscher W. Acute changes in the neuronal expression of GABA and glutamate decarboxylase isoforms in the rat piriform cortex following status epilepticus. Neuroscience (2006) 141:2177-94. doi:10.1016/j.neuroscience.2006.05.040

178. Brandt C, Potschka H, Löscher W, Ebert U. N-methyl-D-aspartate receptor blockade after status epilepticus protects against limbic brain damage but not against epilepsy in the kainate model of temporal lobe epilepsy. Neuroscience (2003) 118:727-40. doi:10.1016/S0306-4522(03)00027-7

179. Myhrer T, Enger S, Aas P. Anticonvulsant impact of lesions in the ventrolateral forebrain of rats challenged with soman. Brain Res (2008) 1226:241-7. doi:10.1016/j.brainres.2008.06.014

180. Ebert U, Rundfeldt C, Löscher W. Development and pharmacological suppression of secondary afterdischarges in the hippocampus of amygdala-kindled rats. Eur J Neurosci (1995) 7:732-41. doi:10.1111/j.1460-9568.1995.tb00677.x

181. Bolkvadze T, Dzhaparidze ND, Zhvaniya MG, Kotariya NT, Tsitsishvili AS. Cellular composition of the piriform cortex of the rat brain in experimental epilepsy. Neurosci Behav Physiol (2006) 36:271-4. doi:10.1007/s11055-0060010-3

182. Lehmann H, Ebert U, Löscher W. Amygdala-kindling induces a lasting reduction of GABA-immunoreactive neurons in a discrete area of the ipsilateral piriform cortex. Synapse (1998) 29:299-309. doi:10.1002/(SICI)10982396(199808)29:4<299::AID-SYN2>3.0.CO;2-0

183. Gernert M, Bloms-Funke P, Ebert U, Löscher W. Kindling causes persistent in vivo changes in firing rates and glutamate sensitivity of central piriform cortex neurons in rats. Neuroscience (2000) 99:217-27. doi:10.1016/S03064522(00)00195-0

184. Teskey GC, Racine RJ. Increased spontaneous unit discharge rates following electrical kindling in the rat. Brain Res (1993) 624:11-8. doi:10.1016/00068993(93)90054-Q

185. Scott BW, Park H, Han H, Wahidie A, Burnham WM. Extrafocal threshold reductions in amygdala-kindled rats. Epilepsia (2010) 51:1729-35. doi:10.1111/ j.1528-1167.2010.02524.x

186. Foster JA, Puchowicz MJ, McIntyre DC, Herkenham M. Activin mRNA induced during amygdala kindling shows a spatiotemporal progression that tracks the spread of seizures. J Comp Neurol (2004) 476:91-102. doi:10.1002/cne.20197

187. Li S, Reinprecht I, Fahnestock M, Racine RJ. Activity-dependent changes in synaptophysin immunoreactivity in hippocampus, piriform cortex, and entorhinal cortex of the rat. Neuroscience (2002) 115:1221-9. doi:10.1016/ S0306-4522(02)00485-2

188. Miller HP, Levey AI, Rothstein JD, Tzingounis AV, Conn PJ. Alterations in glutamate transporter protein levels in kindling-induced epilepsy. J Neurochem (1997) 68:1564-70. doi:10.1046/j.1471-4159.1997.68041564.x

189. Henderson AK, Galic MA, Teskey GC. Cortical kindling induces elevated levels of AMPA and GABA receptor subunit mRNA within the amygdala/piriform region and is associated with behavioral changes in the rat. Epilepsy Behav (2009) 16:404-10. doi:10.1016/j.yebeh.2009.08.015

190. Prince HC, Tzingounis AV, Levey AI, Conn PJ. Functional downregulation of GluR2 in piriform cortex of kindled animals. Synapse (2000) 38:489-98. doi:10.1002/1098-2396(20001215)38:4<489:AID-SYN15>3.0.CO;2-N

191. Gavrilovici C, Pollock E, Everest M, Poulter MO. The loss of interneuron functional diversity in the piriform cortex after induction of experimental epilepsy. Neurobiol Dis (2012) 48:317-28. doi:10.1016/j.nbd.2012.07.002
192. Okabe A, Ohno K, Toyoda H, Yokokura M, Sato K, Fukuda A. Amygdala kindling induces upregulation of mRNA for NKCC1, a $\mathrm{Na}+, \mathrm{K}+-2 \mathrm{Cl}$ cotransporter, in the rat piriform cortex. Neurosci Res (2002) 44:225-9. doi:10.1016/S0168-0102(02)00093-7

193. Vessal M, Dugani CB, Solomon DA, McIntyre Burnham W, Ivy GO. Might astrocytes play a role in maintaining the seizure-prone state? Brain Res (2005) 1044:190-6. doi:10.1016/j.brainres.2005.02.058

194. Pollock E, Everest M, Brown A, Poulter MO. Metalloproteinase inhibition prevents inhibitory synapse reorganization and seizure genesis. Neurobiol Dis (2014) 70:21-31. doi:10.1016/j.nbd.2014.06.003

195. Engel J, Wolfson L, Brown L. Anatomical correlates of electrical and behavioral events related to amygdaloid kindling. Ann Neurol (1978) 3:538-44. doi:10.1002/ana.410030615

196. Clark M, Post RM, Weiss SR, Cain CJ, Nakajima T. Regional expression of c-fos mRNA in rat brain during the evolution of amygdala kindled seizures. Brain Res Mol Brain Res (1991) 11:55-64. doi:10.1016/0169-328X(91)90021-O

197. Racine RJ, Mosher M, Kairiss EW. The role of the pyriform cortex in the generation of interictal spikes in the kindled preparation. Brain Res (1988) 454:251-63. doi:10.1016/0006-8993(88)90825-6

198. Schwabe K, Ebert U, Löscher W. Bilateral lesions of the central but not anterior or posterior parts of the piriform cortex retard amygdala kindling in rats. Neuroscience (2000) 101:513-21. doi:10.1016/S0306-4522(00)00407-3

199. Wahnschaffe U, Ebert U, Löscher W. The effects of lesions of the posterior piriform cortex on amygdala kindling in the rat. Brain Res (1993) 615:295-303 doi:10.1016/0006-8993(93)90041-K

200. Racine RJ, Paxinos G, Mosher JM, Kairiss EW. The effects of various lesions and knife-cuts on septal and amygdala kindling in the rat. Brain Res (1988) 454:264-74. doi:10.1016/0006-8993(88)90826-8

201. Stevens JR, Phillips I, de Beaurepaire R. $\gamma$-Vinyl GABA in endopiriform area suppresses kindled amygdala seizures. Epilepsia (1988) 29:404-11. doi:10.1111/ j.1528-1157.1988.tb03739.x

202. Schwabe K, Ebert U, Löscher W. The central piriform cortex: anatomical connections and anticonvulsant effect of GABA elevation in the kindling model. Neuroscience (2004) 126:727-41. doi:10.1016/j.neuroscience.2004.04.022

203. Namvar S, Mirnajafi-Zadeh J, Fathollahi Y, Zeraati M. The role of piriform cortex adenosine A1 receptors on hippocampal kindling. Can J Neurol Sci (2008) 35:226-31. Available from: http://cjns.metapress.com/content/ 34R82677JQ3H2404

204. Rezvani ME, Mirnajafi-Zadeh J, Fathollahi Y, Palizvan MR. Anticonvulsant effect of A1 but not A2A adenosine receptors of piriform cortex in amygdalakindled rats. Can J Physiol Pharmacol (2007) 85:606-12. doi:10.1139/y07-046

205. Wada J, Tsuchimochi H. Role of the claustrum in convulsive evolution of visual afferent and partial nonconvulsive seizures in primates. Epilepsia (1997) 38:897-906. doi:10.1111/j.1528-1157.1997.tb01255.x

206. Kwan P, Arzimanoglou A, Berg AT, Brodie MJ, Allen Hauser W, Mathern G, et al. Definition of drug resistant epilepsy: consensus proposal by the ad hoc Task Force of the ILAE Commission on Therapeutic Strategies. Epilepsia (2010) 51:1069-77. doi:10.1111/j.1528-1167.2009.02397.x

207. Schmidt D, Löscher W. Drug resistance in epilepsy: putative neurobiologic and clinical mechanisms. Epilepsia (2005) 46:858-77. doi:10.1111/j.1528- 1167. 2005.54904.x

208. Rogawski MA, Johnson MR. Intrinsic severity as a determinant of antiepileptic drug refractoriness. Epilepsy Curr (2008) 8:127-30. doi:10.1111/j.1535-7511. 2008.00272.x

209. Berg AT, Langfitt J, Shinnar S, Vickrey BG, Sperling MR, Walczak T, et al. How long does it take for partial epilepsy to become intractable? Neurology (2003) 60:186-90. doi:10.1212/01.WNL.0000031792.89992.EC

210. Kwong KL, Sung WY, Wong SN, So KT. Early predictors of medical intractability in childhood epilepsy. Pediatr Neurol (2003) 29:46-52. doi:10.1016/S08878994(03)00028-6

211. Sisodiya SM, Lin W-R, Harding BN, Squier MV, Thom M. Drug resistance in epilepsy: expression of drug resistance proteins in common causes of refractory epilepsy. Brain (2002) 125:22-31. doi:10.1093/brain/awf002

212. Volk HA, Löscher W. Multidrug resistance in epilepsy: rats with drugresistant seizures exhibit enhanced brain expression of P-glycoprotein compared with rats with drug-responsive seizures. Brain (2005) 128:1358-68. doi:10.1093/brain/awh437

213. Feldmann M, Asselin M-C, Liu J, Wang S, McMahon A, Anton-Rodriguez J, et al. P-glycoprotein expression and function in patients with temporal lobe 
epilepsy: a case-control study. Lancet Neurol (2013) 12:777-85. doi:10.1016/ S1474-4422(13)70109-1

214. Fang M, Xi Z-Q, Wu Y, Wang X-F. A new hypothesis of drug refractory epilepsy: neural network hypothesis. Med Hypotheses (2011) 76:871-6. doi:10.1016/j.mehy.2011.02.039

215. Grant AC. Interictal perceptual function in epilepsy. Epilepsy Behav (2005) 6:511-9. doi:10.1016/j.yebeh.2005.03.016

216. Eskenazi B, Cain WS, Novelly RA, Mattson R. Odor perception in temporal lobe epilepsy patients with and without temporal lobectomy. Neuropsychologia (1986) 24:553-62. doi:10.1016/0028-3932(86)90099-0

217. Haehner A, Henkel S, Hopp P, Hallmeyer-Elgner S, Reuner U, Reichmann H, et al. Olfactory function in patients with and without temporal lobe resection. Epilepsy Behav (2012) 25:477-80. doi:10.1016/j.yebeh.2012.09.011

218. Kohler CG, Moberg PJ, Gur RE, O’Connor MJ, Sperling MR, Doty RL. Olfactory dysfunction in schizophrenia and temporal lobe epilepsy. Neuropsychiatry Neuropsychol Behav Neurol (2001) 14:83-8.

219. Martinez BA, Cain WS, de Wijk RA, Spencer DD, Novelly RA, Sass KJ. Olfactory functioning before and after temporal lobe resection for intractable seizures. Neuropsychology (1993) 7:351-63. doi:10.1037/0894-4105.7.3.351

220. Savic I, Bookheimer SY, Fried I, Engel J Jr. Olfactory bedside test. A simple approach to identify temporo-orbitofrontal dysfunction. Arch Neurol (1997) 54:162-8. doi:10.1001/archneur.1997.00550140038010

221. Dimov D. [Olfactory function in epilepsy]. Vestn Otorinolaringol (1973) 35:22-3.

222. Kareken DA, Mosnik DM, Doty RL, Dzemidzic M, Hutchins GD. Functional anatomy of human odor sensation, discrimination, and identification in health and aging. Neuropsychology (2003) 17:482-95. doi:10.1037/0894-4105. 17.3.482

223. Hudry J. Olfactory short-term memory and related amygdala recordings in patients with temporal lobe epilepsy. Brain (2003) 126:1851-63. doi:10.1093/ brain/awg 192

224. West SE, Doty RL, O'Connor MJ, Sperling MR. Pre- and post-operative studies of olfactory function in patients with anterior temporal lobectomy. In: Proceedings of the Fifteenth Annual Meeting of the Association for Chemoreception Sciences, Sarasota, Florida. Chem Senses (1993) 21:649.

225. Carroll B, Richardson JT, Thompson P. Olfactory information processing and temporal lobe epilepsy. Brain Cogn (1993) 22:230-43. doi:10.1006/brcg. 1993.1036

226. Abraham A, Mathai KV. The effect of right temporal lobe lesions on matching of smells. Neuropsychologia (1983) 21:277-81. doi:10.1016/0028-3932(83) 90045-3

227. Rausch R, Serafetinides EA, Crandall PH. Olfactory memory in patients with anterior temporal lobectomy. Cortex (1977) 13:445-52. doi:10.1016/S00109452(77)80024-5

228. Gordon HW, Sperry RW. Lateralization of olfactory perception in the surgically separated hemispheres of man. Neuropsychologia (1969) 7:111-20. doi:10.1016/0028-3932(69)90009-8

229. Savage R, Combs DR, Pinkston JB, Advokat C, Gouvier WD. The role of temporal lobe and orbitofrontal cortices in olfactory memory function. Arch Clin Neuropsychol (2002) 17:305-18. doi:10.1016/S0887-6177(01)00114-7

230. Hummel T, Henkel S, Negoias S, Galván JRB, Bogdanov V, Hopp P, et al. Olfactory bulb volume in patients with temporal lobe epilepsy. J Neurol (2013) 260:1004-8, doi:10.1007/s00415-012-6741-x

231. Centeno M, Vollmar C, Stretton J, Symms MR, Thompson PJ, Richardson MP, et al. Structural changes in the temporal lobe and piriform cortex in frontal lobe epilepsy. Epilepsy Res (2014) 108:978-81. doi:10.1016/j.eplepsyres.2014.03.001

232. Hummel T, Pauli E, Schüler P, Kettenmann B, Stefan H, Kobal G. Chemosensory event-related potentials in patients with temporal lobe epilepsy. Epilepsia (1995) 36:79-85. doi:10.1111/j.1528-1157.1995.tb01670.x
233. Ciumas C, Lindström P, Aoun B, Savic I. Imaging of odor perception delineates functional disintegration of the limbic circuits in mesial temporallobe epilepsy. Neuroimage (2008) 39:578-92. doi:10.1016/j.neuroimage.2007. 09.004

234. Gowers W. Epilepsy and Other Chronic Convulsive Disorders: Their Causes, Symptoms and Treatment. London: J \& A Churchill (1881).

235. Jaseja H. Scientific basis behind traditional practice of application of "shoesmell" in controlling epileptic seizures in the eastern countries. Clin Neurol Neurosurg (2008) 110:535-8. doi:10.1016/j.clineuro.2008.02.006

236. Efron R. The effect of olfactory stimuli in arresting uncinate fits. Brain (1956) 79:267-81. doi:10.1093/brain/79.2.267

237. Efron R. The conditioned inhibition of uncinate fits. Brain (1957) 80:251-62. doi:10.1093/brain/80.2.251

238. Ebert U, Löscher W. Strong olfactory stimulation reduces seizure susceptibility in amygdala-kindled rats. Neurosci Lett (2000) 287:199-202. doi:10.1016/ S0304-3940(00)01161-7

239. Hughes JR, Andy OJ. The human amygdala. I. Electrophysiological responses to odorants. Electroencephalogr Clin Neurophysiol (1979) 46:428-43. doi:10. 1016/0013-4694(79)90144-5

240. Pereira EAC, Green AL, Stacey RJ, Aziz TZ. Refractory epilepsy and deep brain stimulation. J Clin Neurosci (2012) 19:27-33. doi:10.1016/j.jocn.2011. 03.043

241. Wyckhuys T, Geerts PJ, Raedt R, Vonck K, Wadman W, Boon P. Deep brain stimulation for epilepsy: knowledge gained from experimental animal models. Acta Neurol Belg (2009) 109:63-80. Available from: http://www.actaneurologica.be/ acta/download/2009-2/01-wyckhuys\%20et\%20al.pdf

242. Esmaeilpour K, Masoumi-Ardakani Y, Sheibani V, Shojaei A, Harandi S, Mirnajafi-Zadeh J. Comparing the anticonvulsant effects of low frequency stimulation of different brain sites on the amygdala kindling acquisition in rats. Basic Clin Neurosci (2013) 4:68-74. Available from: http://bcn.iums.ac.ir/ browse.php?a_code $=$ A-10-1-170\&slc_lang $=$ en\&sid $=1$

243. Yang L-X, Jin C-L, Zhu-Ge Z-B, Wang S, Wei E-Q, Bruce IC, et al. Unilateral lowfrequency stimulation of central piriform cortex delays seizure development induced by amygdaloid kindling in rats. Neuroscience (2006) 138:1089-96. doi:10.1016/j.neuroscience.2005.12.006

244. Zhu-Ge Z-B, Zhu Y-Y, Wu D-C, Wang S, Liu L-Y, Hu W-W, et al. Unilateral low-frequency stimulation of central piriform cortex inhibits amygdaloidkindled seizures in Sprague-Dawley rats. Neuroscience (2007) 146:901-6. doi:10.1016/j.neuroscience.2007.02.014

245. Ghorbani P, Mohammad-Zadeh M, Mirnajafi-Zadeh J, Fathollahi Y. Effect of different patterns of low-frequency stimulation on piriform cortex kindled seizures. Neurosci Lett (2007) 425:162-6. doi:10.1016/j.neulet.2007.08.023

Conflict of Interest Statement: The authors declare that the research was conducted in the absence of any commercial or financial relationships that could be construed as a potential conflict of interest.

Received: 27 July 2014; accepted: 22 November 2014; published online: 08 December 2014

Citation: Vaughan DN and Jackson GD (2014) The piriform cortex and human focal epilepsy. Front. Neurol. 5:259. doi: 10.3389/fneur.2014.00259

This article was submitted to Epilepsy, a section of the journal Frontiers in Neurology. Copyright (C) 2014 Vaughan and Jackson. This is an open-access article distributed under the terms of the Creative Commons Attribution License (CC BY). The use, distribution or reproduction in other forums is permitted, provided the original author(s) or licensor are credited and that the original publication in this journal is cited, in accordance with accepted academic practice. No use, distribution or reproduction is permitted which does not comply with these terms. 